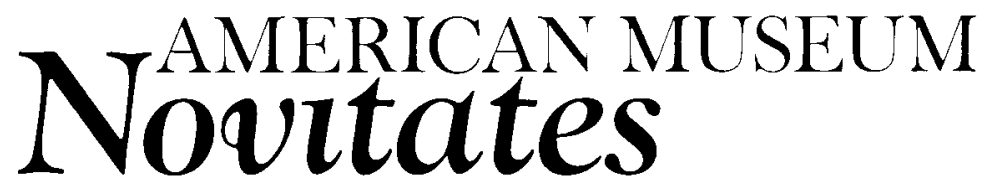

PUBLISHED BY THE AMERICAN MUSEUM OF NATURAL HISTORY CENTRAL PARK WEST AT 79TH STREET, NEW YORK, NY 10024 Number 3295, 25 pp., 61 figures, 3 tables

April 25, 2000

\title{
A Cladistic Analysis of the Therini: A New Synonym of the Cidariini (Lepidoptera: Geometridae, Larentiinae)
}

\author{
SEI-WOONG CHOI ${ }^{1}$
}

\begin{abstract}
To test the monophyly of the tribe Therini and resolve the relationship between Therini and Cidariini, 49 morphological characters of 38 species of Thera and related genera were analyzed cladistically. Five taxa from the Cidariini were chosen for outgroup comparisons. Monophyly of the Therini was not supported and the Therini newly synonymized with Cidariini. Five genera, Praethera Viidalepp, Thera Stephens, Pennithera Viidalepp, Heterothera Inoue, and Diathera Choi, are redefined monophyletically, and two new monotypic genera are proposed: Costicoma, n. gen. and Fascilunaria, n. gen. The combination Thera firmata (Hübner) is proposed. Relationships among the ingroup taxa are largely resolved: (Fascilunaria (Heterothera (Thera (Diathera, Pennithera)))). Synapomorphies and a diagnosis of each genus are given, and a key to the ingroup genera is provided.
\end{abstract}

\section{INTRODUCTION}

The geometrid subfamily Larentiinae is distributed worldwide and approximately 39 genera are shared among the Palearctic and Nearctic regions. Therini is a tribe of the Larentiinae and the type genus Thera Stephens occurs in the Holarctic region. Pierce (1914) placed Thera as a distinct group, Therinae, which is now referred to as a tribe (Hollo- way, 1997). Concurrently, Prout (1914) placed Thera as a subgenus within Cidaria, sensu lato, and subdivided the genus into two subgenera separated by the structure of the male antennae (shortly ciliated vs. bipectinate). Later, Prout (1941) upgraded Thera to the generic level.

Since the works of Pierce and Prout, several new genera and species within the Therini have been described, mainly from the

\footnotetext{
${ }^{1}$ Kalbfleisch Fellow, Division of Invertebrate Zoology, American Museum of Natural History.
} 

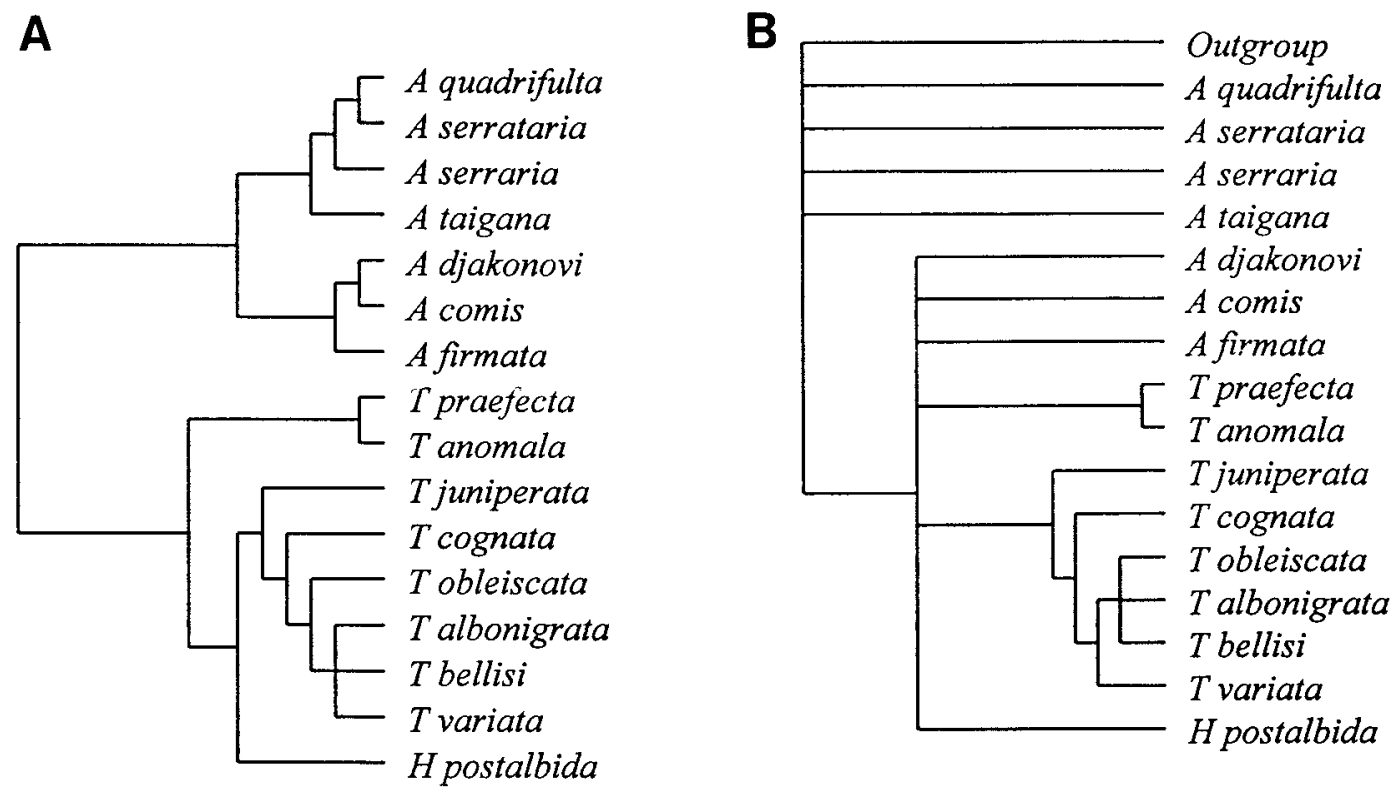

Fig. 1. Viidalepp's (1980) generic relationships of Thera and related genera. A. Viidalepp's phylogram, redrawn from his fig. 1; B. the strict consensus cladogram of 55 cladograms from the reanalysis, see appendix 2. Abbreviations: A Asaphodes, $\mathbf{H}$ Heterothera, T Thera.

Oriental region. Inoue (1943) described the monotypic genus Heterothera, and Viidalepp (1980) subdivided Therini (sensu Prout) into five genera: Asaphodes Meyrick sensu Viidalepp, Pennithera Viidalepp, Heterothera Inoue, Praethera Viidalepp, and Thera, although the first one (Asaphodes sensu Viidalepp) was replaced by Viidaleppia by Inoue (1982). Later, Choi (1997) synonymized Viidaleppia with Heterothera and further proposed a genus from southwestern China, Diathera (Choi, 1999). Presently the Therini includes 5 genera and about 50 species worldwide: Thera Stephens (1831), Praethera Viidalepp (1980), Pennithera Viidalepp (1980), Heterothera Inoue (1943), and Diathera Choi (1999). Since most species of Asaphodes occur in Australia and New Zealand and are closely related to Xanthorhoe Hübner (Dugdale, 1988), this genus is excluded from the Therini.

Here I present a cladistic analysis of the Therini based on adult morphology. The analysis will focus on two things. First, a test of the monophyly of the Therini and an examination of relationships between Therini and Cidariini. Since my previous cladistic analysis (Choi, 1997), several papers have described additional members of the Cidariini (Paradysstroma Choi, 1998 and Pseudodysstroma Heydemann, 1961) and Therini (Heterothera and Diathera) (Choi, 1998a, 1998b, 1999) and confused our understanding of the phylogeny of these moths. Many synapomorphies for Pennithera, Heterothera, and Thera were found to be homoplastic, also occurring in Paradysstroma and Pseudodysstroma. For example, the presence of cucullus hairs and saccular processes in the male genitalia were synapomorphic for Heterothera, but these occur in Pseudodysstroma and Diathera as well. Similarly the corona-shaped processes at the distal part of the aedeagus, an autapomorphic character for Thera, is also observed in several species of Heterothera (see Choi, 1998a). Such homoplasy prompted the present analysis.

The second focal point is to understand the generic placement of Thera exangulata (Warren) and T. cyphoschema Prout. These taxa were included in the Therini by Prout (1938, 1941). Although I have described the genitalia and other aspects of morphology of these species (Choi, 1998a), the placement of these taxa remains uncertain.

Members of the Therini occur mainly in 
Asia, except for Thera, which is Holarctic in distribution. Many of the Asian species are endemic to southwestern China, Taiwan, or northern India: four species of Pennithera and two species of Heterothera are endemic to Taiwan; six species of Heterothera, and all species of Diathera are endemic to southwestern China; and eight species of Heterothera are endemic to northern India. Thus, understanding of interrelationships of Thera and other Asian genera will provide the basis for future biogeographic studies.

\section{MATERIALS AND METHODS}

\section{TAXa And Characters}

The ingroup comprised 38 species from the Holarctic and northern Oriental regions: 7 species of Thera, 1 Praethera, 8 Pennithera, 17 Heterothera, 3 Diathera, as well as "Thera cyphoschema" and " $T$. exangulata" (see appendix 1). In total, 49 characters from the genitalia and other morphological structures were used.

Adult specimens were obtained from the following museums and private collections: American Museum of Natural History, New York; Bulgarian Natural History Museum, Sofia; Hungarian Natural History Museum, Budapest; Institute of Botany and Zoology, Tartu; private collection of Katsumi Yazaki, Tokyo; The Natural History Museum, London; Zoologisches Forschungsinstitut und Museum Alexander Koenig, Bonn; Zoological Museum, Helsinki; and Zoologische Staatssammlung München, Munich. Male and female genitalia were prepared by soaking the abdomen in cold $10 \% \mathrm{KOH}$ for approximately 24 hours. Scales and tissues were removed, stained with Chlorazol Black, and mounted on slides in Euparal. Electron micrographs were taken with a Hitachi S4700 Field Emission Scanning Electron Microscope (FE-SEM). Morphological terms follow Forbes (1948) and Scoble (1992).

\section{Cladistic Analysis}

The data matrix is provided in table 1 . Five outgroups were used to root cladograms, all belonging to the tribe Cidariini: Cidaria fulvata (Forster), Plemyria rubiginata (Denis and Schiffermüller), Dysstroma truncatum (Hufnagel), Paradysstroma corussarium (Oberthür), and Pseudodysstroma albovenosatum (Heydemann). The choice of these outgroups was based on (1) a close relationship as shown by a previous cladistic analysis ( $C$. fulvata, $P$. rubiginata, and $D$. truncatum; Choi, 1997) and (2) the fact that they share apomorphic characters with ingroup taxa for which ingroup relationships are ambiguous (Paradysstroma corussarium and Pseudodysstroma albovenosatum).

A parsimony-based computer program, NONA (Goloboff, 1993; Ver. 1.5; hold*hold/ 30 mult*15), was used to find the most parsimonious trees. Multistate characters were treated as unordered during analyses.

\section{ACKNOWLEDGMENTS}

My sincere thanks to Jaan Viidalepp for providing material and translating his work (1980) into English and to David Grimaldi, Jim Miller, Fred Rindge, Toby Schuh (AMNH), Kauri Mikkola, and Malcolm Scoble for commenting on several versions of this manuscript and to Katsumi Yazaki (Tokyo), Kim Goodger (BMNH), Axel Hausmann (ZSM), and Dieter Stüning (ZFMK) for loaning material. Angela Klaus (AMNH) provided helpful assistance with scanning electron microscopy. I am very grateful to David Grimaldi, Michael Engel, Michael Pogue, and Jim Troubridge for reading the manuscript and offering appreciated criticism.

\section{RESULTS AND DISCUSSION \\ CHARACTER ANALYSIS}

Of the 49 characters, numbers $0-11$ were from the head, thorax, and wing patterns; numbers $12-35$ were from the male genitalia; and numbers 36-48 from the female genitalia.

\section{HEAD AND Body (figs. 2-23)}

0. Antennae of male: (O) filiform; (1) pectinate. It is usual for species of moths in the Larentiinae to be diagnosed on the basis of bipectinate male antennae. Prout (1914) suggested that the groupings based on the antennal morphology of males or of both sexes do not always form natural taxa. However, even 
TABLE 1

Data Matrix for Five Outgroup and 38 Ingroup Taxa

Characters and their states are discussed in the text. Missing characters are coded as question marks (?).

111111111122222222223333333333444444444 0123456789012345678901234567890123456789012345678

C. fulvata

$P$. rubiginata

D. truncatum

Ps. albovenosatum

$P d$. corussarium

T. exangulata

$T$. cyphoschema

T. variata

T. juniperata

T. vetustata

T. cognata

$T$. contractata

T. obeliscata

$T$. cupressata

Pe.comis

Pe. abolla

Pe. djakonovi

Pe.lugubris

Pe. subcomis

Pe, subalpina

Pe. manifesta

Pe. distractata

Pr. praefecta

$H$. consimilis

H. hoenei

$H$. firmata

H. postalbida

H. tephroptilus

H. sororcula

H. serraria

$H$. serrataria

H. kurenzovi

H. quadrifulta

H. taigana

H. incerta

H. etes

H. dentifasciata

H. yunnanensis

H. eclinosis

H. undulata

Di. fluctuata

Di. metacolorata

Di. brunneata
0100000000000000010000000000000101000000010000000 0011012000000000010000010201000100110000011010001 0011110100000100010000000000000000110000000000110 0011012010100100010000000000011111000020011100000 0011112000000000010000201210000101320100001100101 0011112000001000010000201011000100000000000000033 1011111001000200010000000010011111000000000010020 0011011100100200000000121200111021000100011000021 0111011000000200000000121200111021000100011000020 0011011000100200000000121200111021000200011020021 0111010000000200000000121210111021000100011020021 0011112100100200000000121210111021000200011000020 0101011000000200000000121200111021000200011000021 0011101000000200000000121200111121000200011000020 1010111010001211000000001110000211111000011100020 1110111010001211000000001111000211111000011100020 1011112100000000000000001010000111000000011100020 110111112000121100000000111000021121 ? ? ? ? ? ? ? ? 1101111120001211000000001110000211211000011101020 $11 ? ? ? 11100001211001010001110000211$ ?? 1000011100020 11 ??? 11010001211000000001110000211211000011100020 101110010000121000011000120100011100 ?? ?? ? ? ? ? ? 0011012000100100011003001010000001120001000000001 1011011110001000010000001300311011330000011200020 1111011100101000011001001200321121000200011000020 1111101001000200001001101210011101110000011100020 0011112000010000011001011001212011330020011000022 1011011000011000001001011000311111330000001200020 0011112100010000011001011000212011330020011100022 1110011100000000011001011210211201130101001100220 1110000100000200000000011210211201130101001100220 1110001100000200000000011210211221330211001100221 1111012100001000011001011000211011120210011200020 1011110000001000011003001001211011330000211100020 1011011110100000011001001000211121000210001000022 1011011111011000010000001300311011330000011200020 1011012100100000000000011300311021330000011100020 0111012010101200001102011301211021210210101100022 0111012010001200001102011301211021230210001100022 1011112000001000001001011001212021330100011100020 0011111000001200111001011200000011002000011001021 0011111000001200111001011200000021002000011001021 0011111000001200111001011200000011002100011000020 he classified Thera using this character, and his groupings were subsequently found to be polyphyletic (Viidalepp, 1980; Choi, 1997). Thera and Praethera have filiform antennae in both sexes, but Pennithera and Heterothera have bipectinate male antennae and filiform female antennae.
A study with the scanning electron microscope shows that there are four modifications of the male antennae; filiform with either short cilia (fig. 19) or long cilia (fig. 18), and pectinate with either short pectinations (fig. 21 ) or long pectinations (figs. 20, 22, 23). It was noted that the pectinations of some No- 

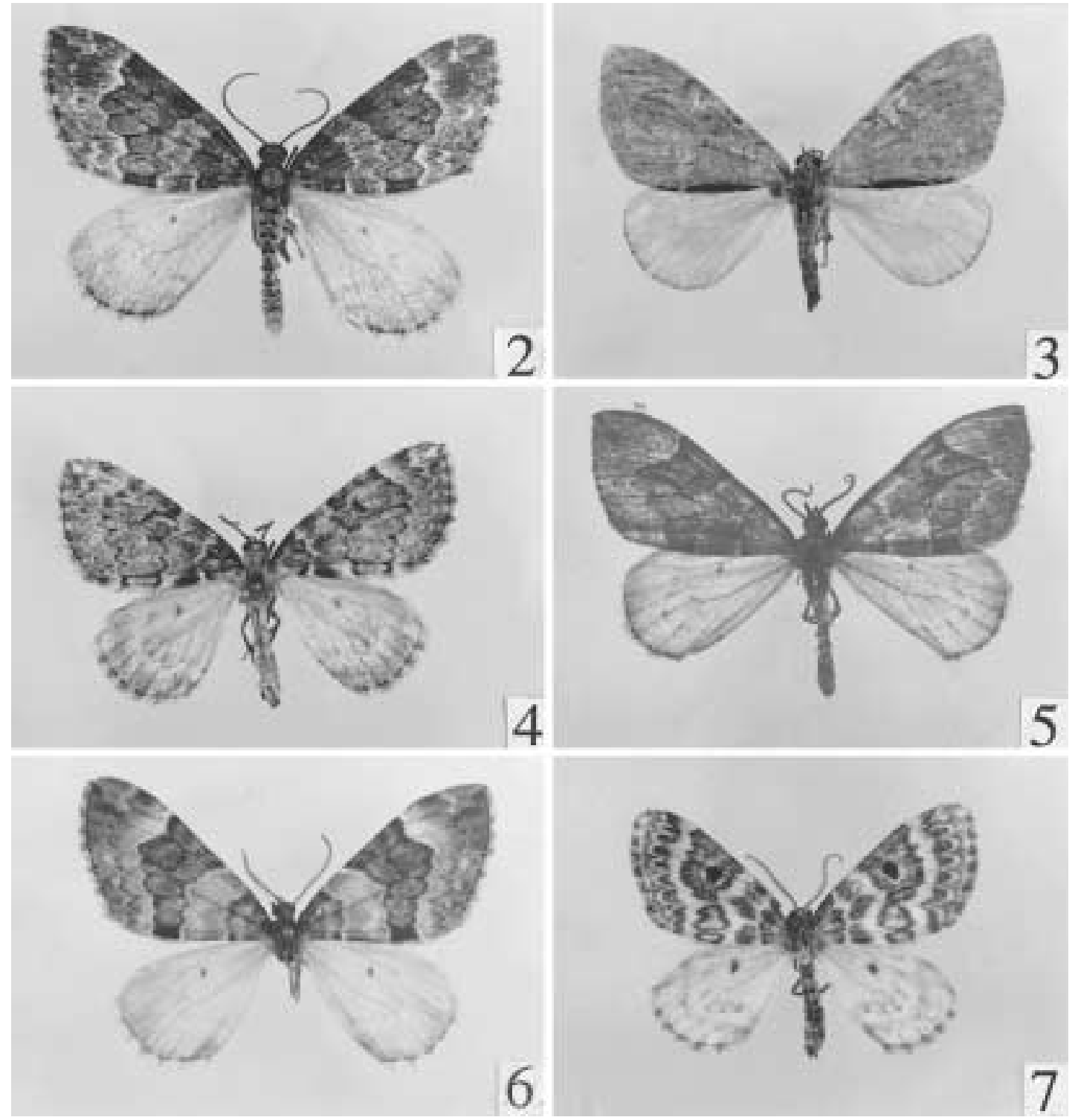

Figs. 2-7. Adults. 2. Praethera praefecta, 3. Heterothera postalbida, 4. H. quadrifulta, 5. H. dentifasciata, 6. H. incerta, 7. H. serraria.

todontidae moths are shorter on one side (Miller, 1991). The difference in length is observed in an ingroup species, Heterothera firmata (fig. 20). Viidalepp (1980) and Inoue (1986a) illustrated the differences in pectination between these genera. The present results show that pectinations are quadripectinate, but differ in orientation, opposite (Heterothera firmata, $H$. taigana, $H$. serraria; figs. 20, 21, 23) or alternate (Pennithera comis; fig. 22). Different lengths of pectinations or cilia are common among the taxa examined and are difficult to code. Thus, I used two simple states, filiform versus pectinate.

1. Vertex: (O) black; (1) distinct with white scales. The vertex can be covered with either black or white scales. Several species 

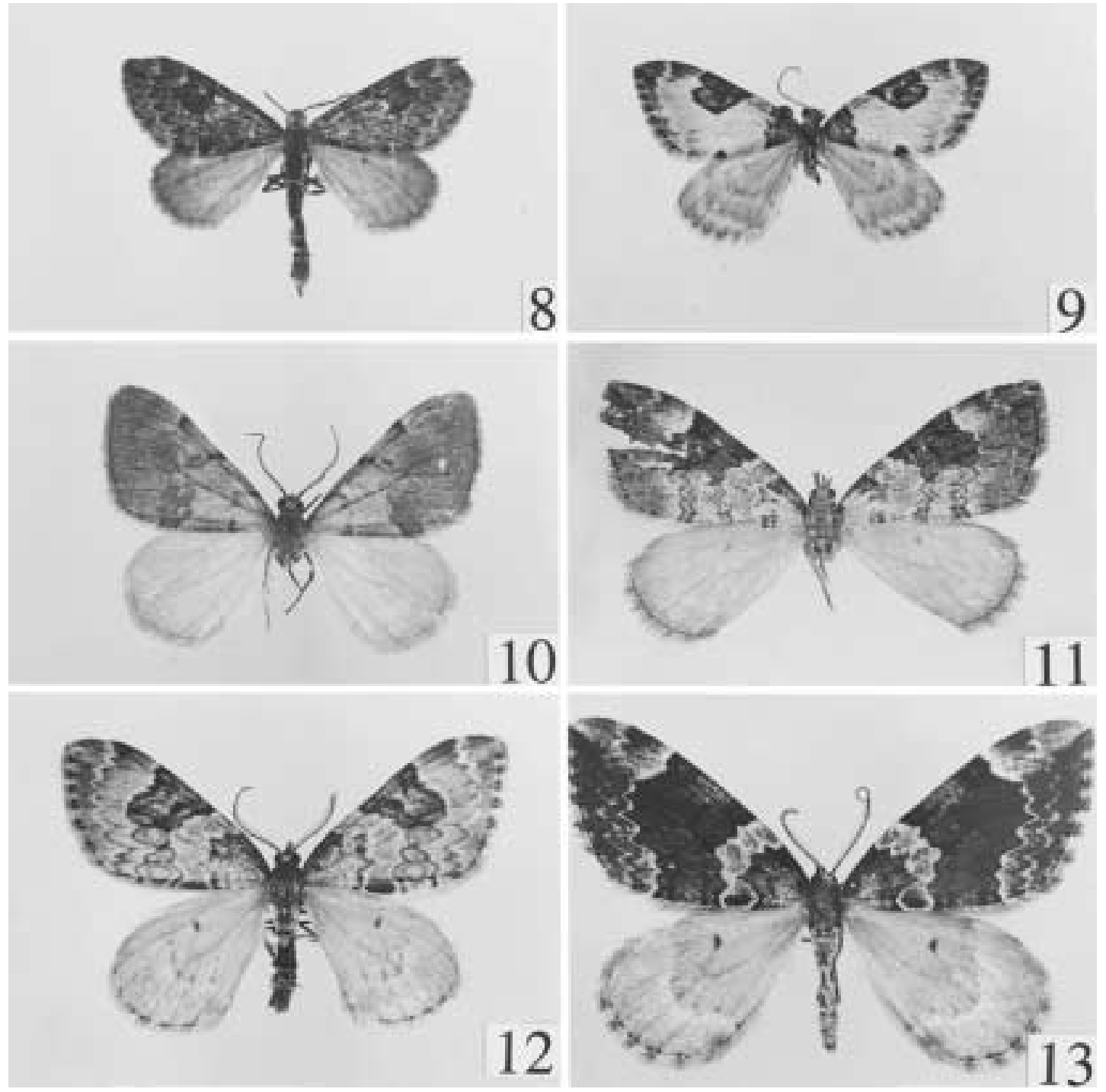

Figs. 8-13. Adults (continued). 8. Thera variata, 9. T. vetustata, 10. T. firmata, 11. Diathera fluctuata, 12. Pennithera comis, 13. P. lugubris.

of Heterothera and Pennithera have white scales on the vertex [e.g., Heterothera eclinosis Choi, H. yunannensis Choi, H. hoenei Choi, Pennithera abolla (Inoue), P. lugubris Inoue, $P$. subalpina Inoue].

2. Frons: $(O)$ covered with uniformly colored scales; (1) mixed white or ochreous and blackish scales. Most of the ingroup taxa have the frons covered with white/ ochreous or blackish scales. Choi (1997) noted also that a rounded frons occurs in Thera and
Heterothera, and that this is an apomorphic character of Cidariini.

3. Foretarsal joints: $(0)$ indistinct in that scales covering them are same color as scales on rest of leg; (1) distinct with white scales. The tarsal joints of forelegs are usually distinct with white scales in Thera, Praethera, and Diathera, but are indistinct in several species of Pennithera [comis (Butler) and abolla (Inoue)] and Heterothera [serraria (Lienig), serrataria (Prout) and kurenzovi 


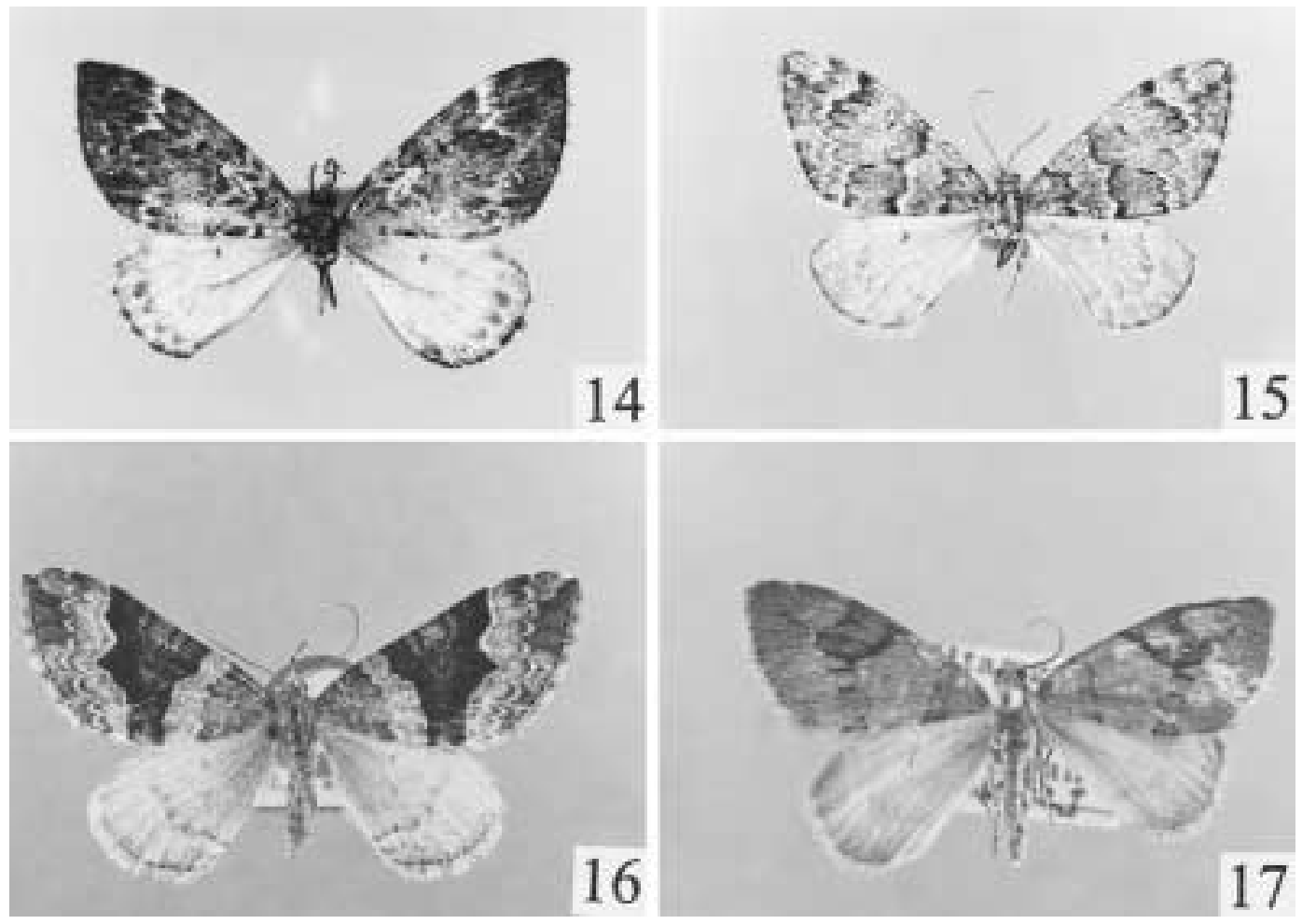

Figs. 14-17. Adults (continued). 14. P. distractata, 15. P. djakonovi, 16. Thera exangulata, 17. T. cyphoschema.

Choi, Viidalepp and Vasjurin]. Obscure tarsal joints are also observed in the outgroup taxa, except in Cidaria fulvata (which has white scales on the joints).

4. Meso- and metathorax: $(0)$ middorsally white; (1) black.

5. Metathorax: $(0)$ with white or yellow tufts; (1) with blackish tufts. Strong tufts occur on the dorsum of the metathorax, and this is often observed in some other taxa of the Larentiinae (Prout, 1914). It was noted that strong tufts occur on the metathorax in members of the Hydriomenini (Forbes, 1948) and Cidariini (Choi, 1997).

\section{WINGS (figs. 2-17)}

6. Shape of antemedial line of forewing, from costa to dorsum: (O) transverse, straight; (1) rounded or medially indented; (2) outwardly oblique.

7. Forewing between basal and ante- medial lines: (O) unicolorous; (1) tinged with black scales.

8. Basal part of forewing dorsally with a black dot: (O) absent; (1) present, but dot small; (2) dot large. The pattern in the area between the basal and antemedial lines of the forewing varies in Therini. Pennithera is distinct by having a black dot on the dorsum. Some species of Heterothera [e.g., quadrifulta (Prout), taigana (Djakonov), incerta Inoue, and consimilis (Warren)] also have a small dot at the dorsum, but they differ from Pennithera in having a black band in the area between basal and antemedial lines (figs. 3, 4, 12, 13).

9. Discal dot of forewing united with costal part of antemedial line: $(0)$ absent; (1) present. Heterothera firmata (Hübner), H. etes (Prout), and Thera cyphoschema have a long, thick discal dot united with the costal part of the antemedial line (fig. 10). 

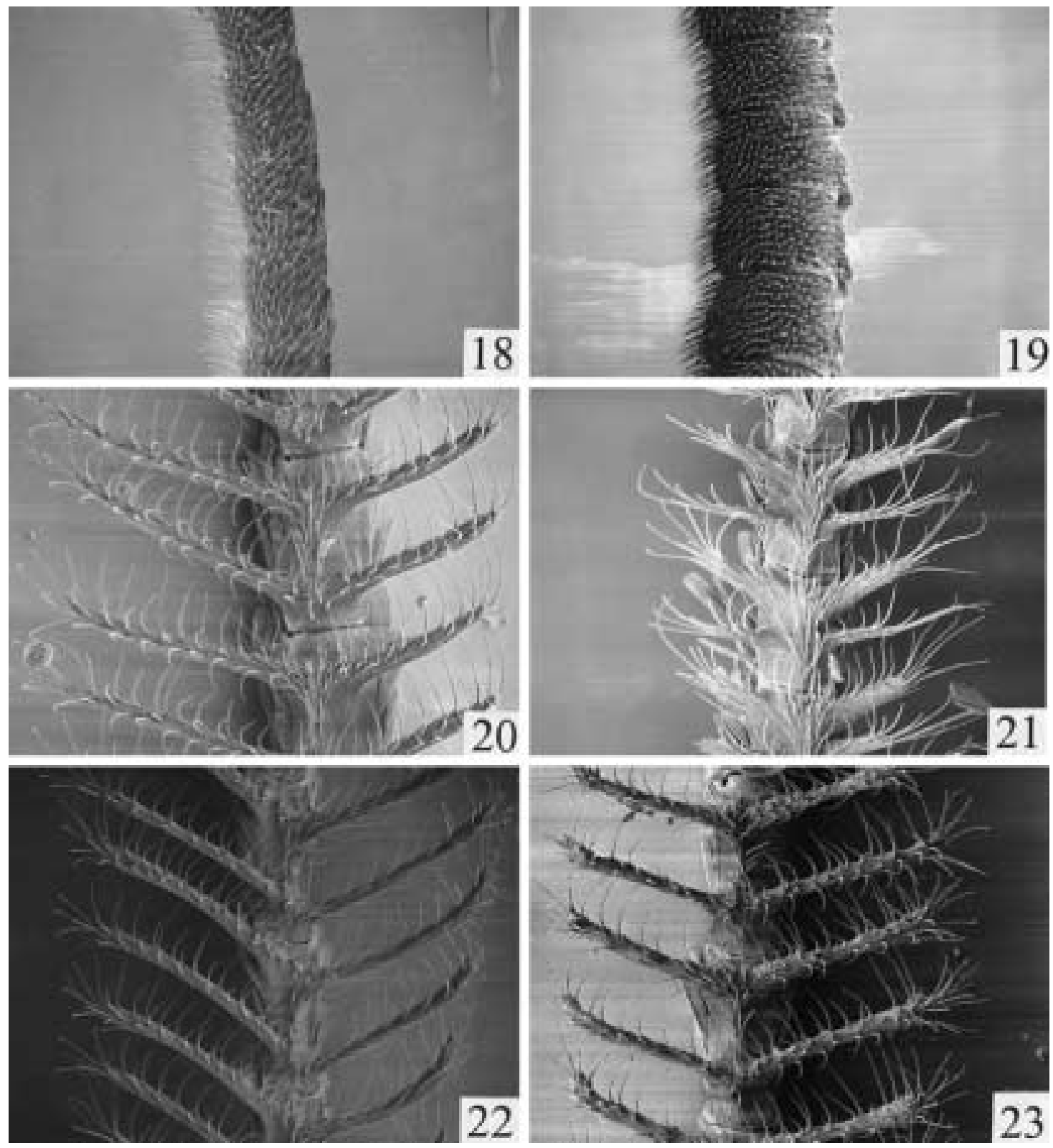

Figs. 18-23. Scanning electron micrographs of male antennae, ventral surface. 18. Thera variata $(\times 110)$, 19. Praethera praefecta $(\times 150), 20$. H. firmata $(\times 150), 21$. Heterothera taigana $(\times 130), 22$. Pennithera comis $(\times 110), 23$. H. serraria $(\times 150)$.

10. Dorsum of central fascia: $(O)$ indistinct and uniform; (1) distinct with black scales.

11. Dorsum of forewing: (O) without a streak; (1) with a black horizontal streak. There are three patterns of black dots in Pen- nithera and Heterothera: (1) a large round dot between the basal and antemedial line (e.g., Pennithera lugubris and P. subcomis) (figs. 12-13), (2) a long horizontal streak along the basal and central fascia (e.g., Heterothera postalbida (Wileman), H. sororcula 
(Bastelberger), H. tephroptilus (Heydemann), H. mussooriensis Choi) (fig. 3), and (3) a blackish spot at the bottom of the central fascia (e.g., H. triangulata Choi) (Choi, 1998a).

\section{Male Genitalia}

12. Length of uncus compared to tegumen (figs. 24-28): (O) shorter; (1) longer. Three species of Diathera show a very long uncus compared to the length of tegumen and this long uncus is also observed in most species of Pennithera and Heterothera.

13. Length of tegumen compared to the total length of vinculum and saccus: $(0)$ same; (1) longer; (2) shorter. Tegumen length is measured against the total length of the vinculum and saccus. This character divides Therini into three groupings: (Praethera), (Pennithera and Thera), and (Heterothera and Diathera). Praethera has a long tegumen, whereas Thera and Pennithera have a short tegumen. Diathera and Heterothera have nearly the same length between the tegumen and the total length of the vinculum and saccus.

14. Width of anterior end of tegumen compared to posterior end (= vinculum): (O) same or slightly shorter; (1) greatly shorter.

15. Shape of anterior end of tegumen (figs. 24-28): (0) slightly invaginated; (1) deeply invaginated.

16. Juxta with strongly sclerotized hairs (fig. 31): (0) absent; (1) present. A unique character of the juxta is observed in all species of Diathera, which is a structure covered with strongly sclerotized hairs.

17. Length of anellus lobe: $(O)$ strongly extended from juxta, reaching more than half of uncus height; (1) slightly extended from juxta, barely reaching bottom of uncus.

18. Shape of anellus lobes (figs. 29-36): (0) digitiform, without expanded body; (1) body expanded.

19. Anellus lobe: (O) unilobed; (1) bilobed.

20. Surface of anellus lobe: $(O)$ smooth; (1) dentate.

21. Shape of anellus lobe: $(0)$ digitiform; (1) rounded; (2) triangular; (3) flattened. The anellus lobes are lateral processes of the juxta that supports the ventral part of the aedeagus and are usually distinct in most groups of Cidariini (Choi, 1997). In Therini, the anellus lobes are distinctive in their length, sclerotization, and for the long apical hairs. The different shapes of the body of the lobes (e.g., triangular, cylindrical, or caplike) provide diagnostic features for the species of Heterothera, Diathera, and Pennithera (figs. 32, 35, 36): Pennithera possesses anellus lobes with a strongly expanded body; and Thera possesses digitiform lobes. But, the shapes of the lobes in Heterothera vary. In particular, the species from southwestern China have greatly modified anellus lobes that are bilobed with an expanded body, often with dentate surfaces: Heterothera yunnanensis, H. eclinosis, and Pennithera distractata (figs. 31, 33, 34).

22. Transtilla: $(0)$ simple, membraneous; (1) platelike, sclerotized; (2) thin, round, sclerotized. The transtilla, the dorsal part of the diaphragma, is usually simple and membraneous in most ingroup taxa, whereas The$r a$ shows a well-developed and sclerotized transtilla. Thera exangulata has a thin, round, sclerotized transtilla.

23. Shape of saccus (figs. 24-28): (O) flat or round and medially slightly projected; (1) medially invaginated; (2) medially strongly projected. The shape of saccus shows three states: (1) broad, flat, or round saccus (Praethera and Pennithera) (fig. 24), (2) medially invaginated or broad saccus (Heterothera and Diathera) (figs. 26, 28), and (3) medially strongly projected (Thera) (fig. 25). In Thera and Pennithera the saccus shows a sclerotized internal ring.

24. Costa of valva (figs. 37-44): (0) membraneous; (1) sclerotized.

25. Shape of costa: $(O)$ flat, not expanded; (1) basally expanded (fig. 40); (2) medially expanded (figs. 38, 41); (3) distally expanded.

26. Costa with a distal sclerotized process: (0) absent; (1) present. The costa, which is the dorsal part of the valva, is frequently modified and strongly sclerotized in Therini and this has been most frequently used by earlier authors (e.g., Viidalepp, 1980; Inoue, 1986a; Choi, 1997). In Thera, Pennithera, and Praethera, the costa has important diagnostic characters: Thera with a 

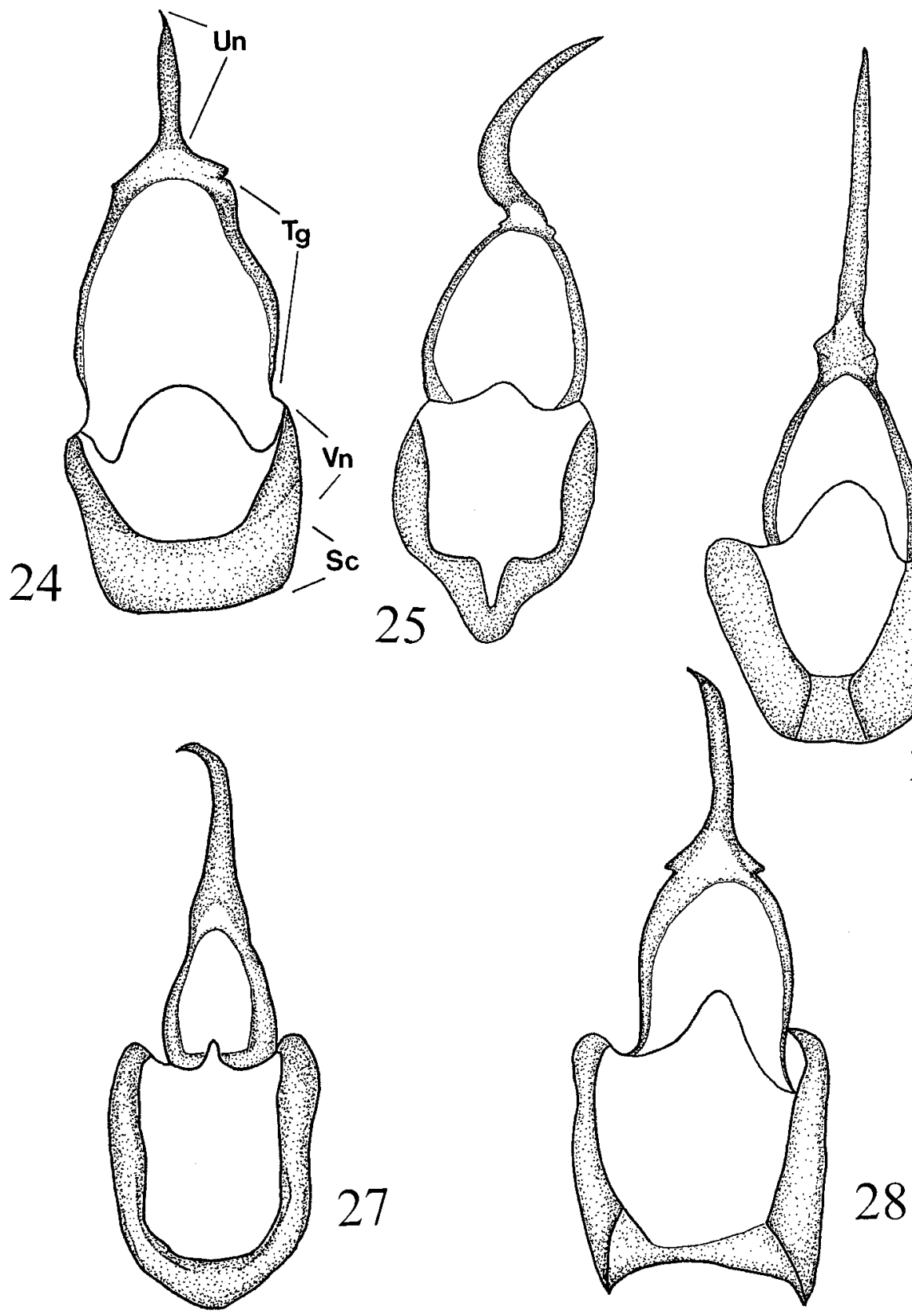

Figs. 24-28. Complex of tegumen, vinculum, and saccus of the male genitalia. 24. Praethera praefecta, 25. Thera variata, 26. Diathera fluctuata, 27. Pennithera comis, 28. Heterothera postalbida. Un uncus, Tg tegumen, Vn vinculum, Sc Saccus.

slender costa with a medial triangular projection; in Pennithera it is basally greatly enlarged and distally sharply pointed; in Diathera the base is minutely toothed and medially greatly enlarged; in Praethera it is long, slender, and distally sharply pointed. However, in Heterothera the shape of the costa varies: with a medial, triangular process sim- 

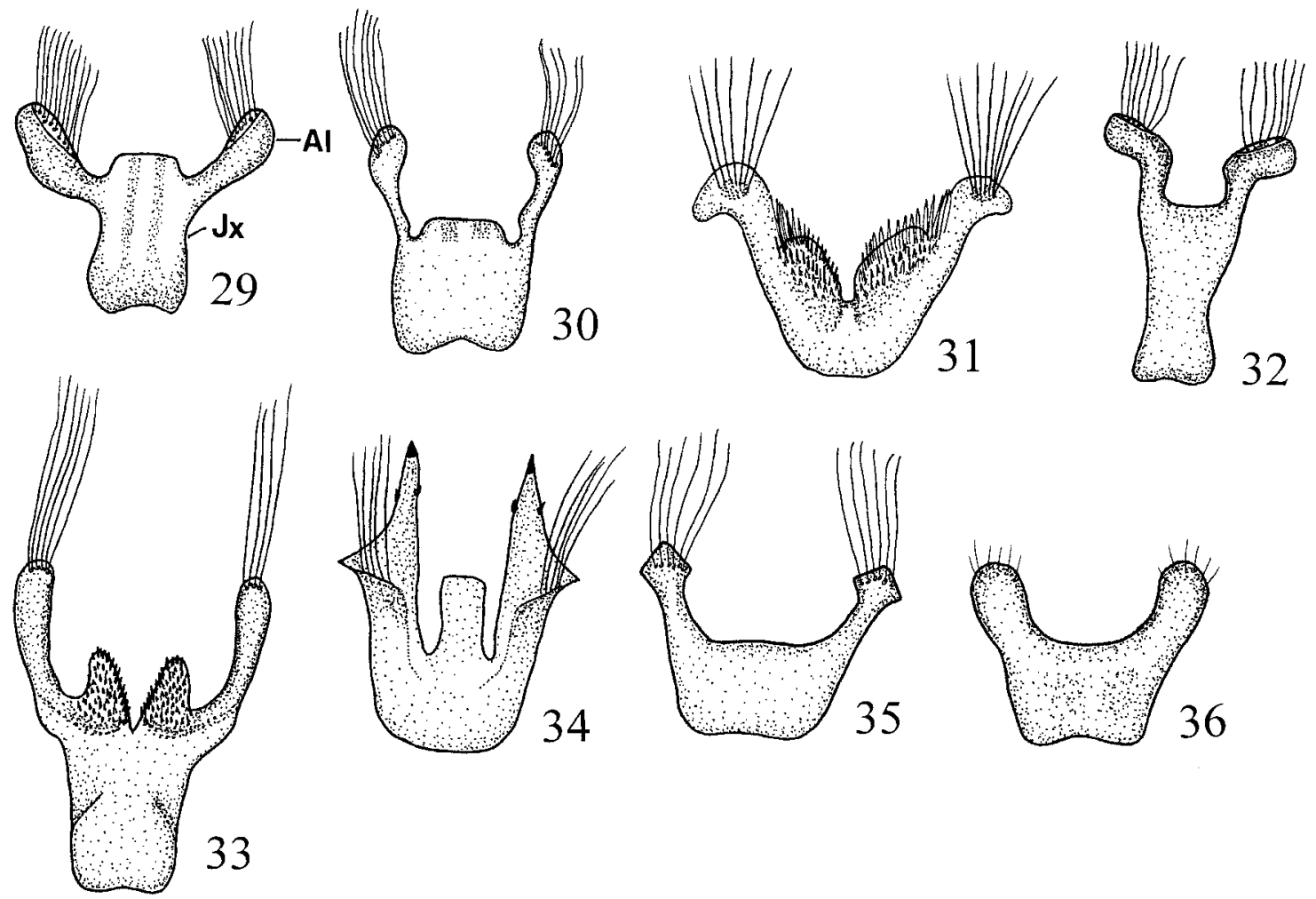

Figs. 29-36. Anellus lobes of male genitalia. 29. Praethera praefecta, 30. Thera variata, 31. Diathera fluctuata, 32. Pennithera comis, 33. P. distractata, 34. Heterothera yunnanensis, 35. H. postalbida, 36. $H$. serraria. Jx juxta, Al anellus lobe.

ilar to Thera (fig. 41), or basally or distally expanded (fig. 42). Choi (1997) noted that the absence of the distal costal process is plesiomorphic.

27. Ventral edge of sacculus: $(0)$ invaginated (figs. 37-41, 44); (1) flat (figs. 42, 43).

28. Shape of dorsal edge of sacculus: $(O)$ indistinct; (1) vertical (fig. 38); (2) straight and oblique (figs. 41, 42); (3) scalloped.

29. Process of sacculus: $(0)$ absent; (1) clawlike or sharply pointed (figs. $38,41,42$, 44); (2) stellate.

30. Number of saccular processes: $(0)$ absent; (1) one; (2) two. The sacculus divides Therini into two groups based on whether it is sclerotized or membraneous. The former includes Thera and Heterothera, the latter Praethera, Diathera and Pennithera. The triangular and sclerotized sacculus diagnoses Heterothera. The sclerotized sacculus is usu- ally coupled with projected processes on the distal part of sacculus, which are often called the "harpe" (Inoue, 1986a). In Heterothera, the process varies from simple and setose (e.g., tephroptilus) to clawlike [e.g., dentifasciata (Hampson)] and stellate (hoenei). Four species of Heterothera have two processes [postalbida, sororcula, undulata (Warren) and obscurata Choi; Choi, 1998a] (fig. 42). This character was also used in Viidalepp's (1980) analysis (his \#2).

31. Width of valva: $(0)$ wider distally (figs. 39, 42); (1) even width (figs. 41, 43); (2) wider basally (fig. 40). The width of the valva diagnoses some members of Therini. In Praethera, Diathera, and Thera, the distal part of valva is wider, whereas in Pennithera the basal part is wider. In Heterothera, the valva is usually wider distally, except for three species (serraria, serrataria and kurenzovi) that have a basally wider valva. 

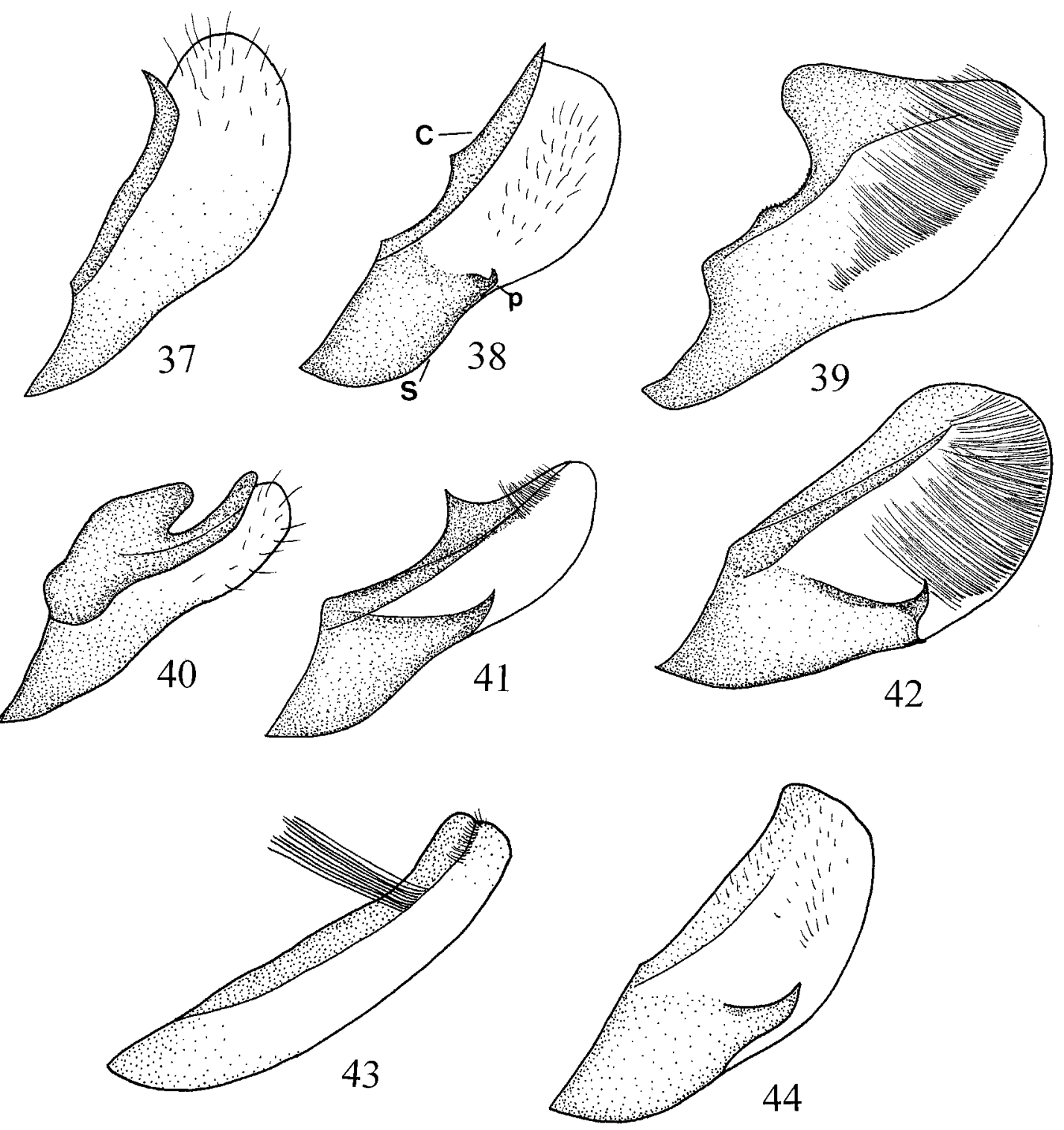

Figs. 37-44. Right valva of male genitalia. 37. Praethera praefecta, 38. Thera variata, 39. Diathera fluctuata, 40. Pennithera comis, 41. Heterothera serraria, 42. Heterothera postalbida, 43. Thera exangulata, 44. Thera cyphoschema. $\mathbf{C}$ costa, $\mathbf{S}$ sacculus, $\mathbf{p}$ saccular process.

32. Distal part of the aedeagus: $(0)$ membraneous, without spines; (1) scobinate (figs. 47, 49, 50); (2) with large spines (fig. 46). Therini has several derived character states on the distal part of the aedeagus. The distal spines in Thera have often been termed cornuti (e.g., Viidalepp, 1980; Choi, 1997), and this state may be a symplesiomorphy of The$r a$ and Heterothera (Choi, 1998a). The scob- ination of the distal part of the aedeagus is morphologically part of the juxta. Because these two parts are fused, they are usually broken in genitalic preparations.

33. Shape of the vesica: $(0)$ large, saclike (fig. 51); (1) tubular (fig. 45)

34. Cornutus: (0) absent; (1) large, spinular; (2) small setae; (3) mixed large and small spines. 
35. Cornuti: (0) absent; (1) grouped into one patch; (2) grouped into several patches; (3) without grouping, scattered. Viidalepp (1980) divided the states of the cornuti into primary and secondary losses. For example, Pennithera djakonovi (Kurentzov) is coded as a primary loss because it lacks cornuti in the vesica. But most species of Thera are coded as secondary because they lack cornuti in the vesica while having spinal processes at the distal part of the aedeagus. Viidalepp also suggested that the presence of cornuti is a derived character in Therini.

The shape of the vesica is coded as tubular or large and saclike. For most ingroup taxa the vesica is tubular, whereas some outgroup taxa (Dysstroma truncatum, Plemyria rubiginata) and Thera exangulata have a large, saclike vesica. Choi (1997) noted that several transformations occur in the vesica of Heterothera: several irregularly shaped diverticulae and many kinds of spinal processes and arrangements of the cornuti.

\section{Female Genitalia}

36. Seventh sternite: $(0)$ simple, membraneous; (1) with sclerotized processes; (2) scobinate. A densely scobinate seventh sternite diagnoses Diathera, while sclerotized processes diagnose Pennithera. In Thera, Praethera, and Heterothera, like outgroup taxa, the seventh sternite is simple and membraneous.

37. Lamella antevaginalis (figs. 52-59): (O) membraneous, without structures; (1) sclerotized with rounded structure; (2) sclerotized with two doughnutlike structures.

38. Lamella antevaginalis with processes: (0) absent; (1) minute spines; (2) large spines.

39. Lamella postvaginalis: $(0)$ membraneous; (1) sclerotized.

40. Lamella postvaginalis with processes: (0) absent; (1) large, barlike processes; (2) large, hornlike processes. Sterigmata (lamellae ante- and postvaginalis) occur around the ostium bursae and they are modified into various forms. Viidalepp (1980) noted that the well-developed sterigmata are plesiomorphic in this group. In Heterothera, these structures vary from simple (e.g., consimilis, etes, and dentifasciata) to spinelike (e.g., postalbida, sororcula, and hoenei) to large hornlike processes (e.g., taigana). In Thera there is no distinction between the lamella antevaginalis and the lamella postvaginalis, because the two structures are fused and semicircular (fig. 53).

41. Length of ductus bursae compared to corpus bursae: $(0)$ shorter; (1) longer.

42. Ductus bursae with a colliculum: $(0)$ present; (1) absent.

43. Ductus bursae: $(0)$ membraneous; (1) sclerotized; (2) with sclerites. The shape of the ductus bursae of Heterothera is variable. Unlike outgroup taxa, in which it is short and membraneous with a colliculum, Heterothera and Pennithera have a sclerotized wall or sclerites in the ductus bursae. The shape of the ductus bursae in these taxa may be long, twisted, or basally greatly expanded. Thera and Diathera have a membraneous ductus bursae, but lack a colliculum.

44. Basal ductus bursae (anterior to antrum): (O) simple, without modification; (1) funnel-shaped; (2) rounded and sclerotized. The basal part of the ductus bursae (anterior to the antrum) is usually simple and membraneous. Two species (Plemyria rubiginata and Thera cyphoschema) have a ductus bursae basally funnel shaped (fig. 58), but in several species of Heterothera (serraria, serrataria and kurenzovi) it is strongly sclerotized with a rounded opening.

45. Distal ductus bursae: (O) membraneous; (1) flattened and sclerotized.

46. Posterior corpus bursae: $(0)$ simple, membraneous; (1) with sclerotized striations; (2) simple, sclerotized. The area between the ductus bursae and the corpus bursae is usually simple and membraneous. But, several species of Heterothera (serraria, serrataria, and kurenzovi) have the corpus bursae strongly sclerotized.

47. Signum: (0) one-process; (1) several, placed in a patchlike band; (2) absent; (3) large, threadlike sclerite. Viidalepp (1980) indicated that the absence of a signum is a derived character of the Therini. In Thera, Pennithera, Heterothera, and Diathera, a signum is absent, whereas in Praethera, a minute nipple-shaped signum occurs (fig. 52). One species (Thera exangulata) shows a large, threadlike signum (fig. 59).

48. Wall of the corpus bursae: $(0) \mathrm{sim}$ - 

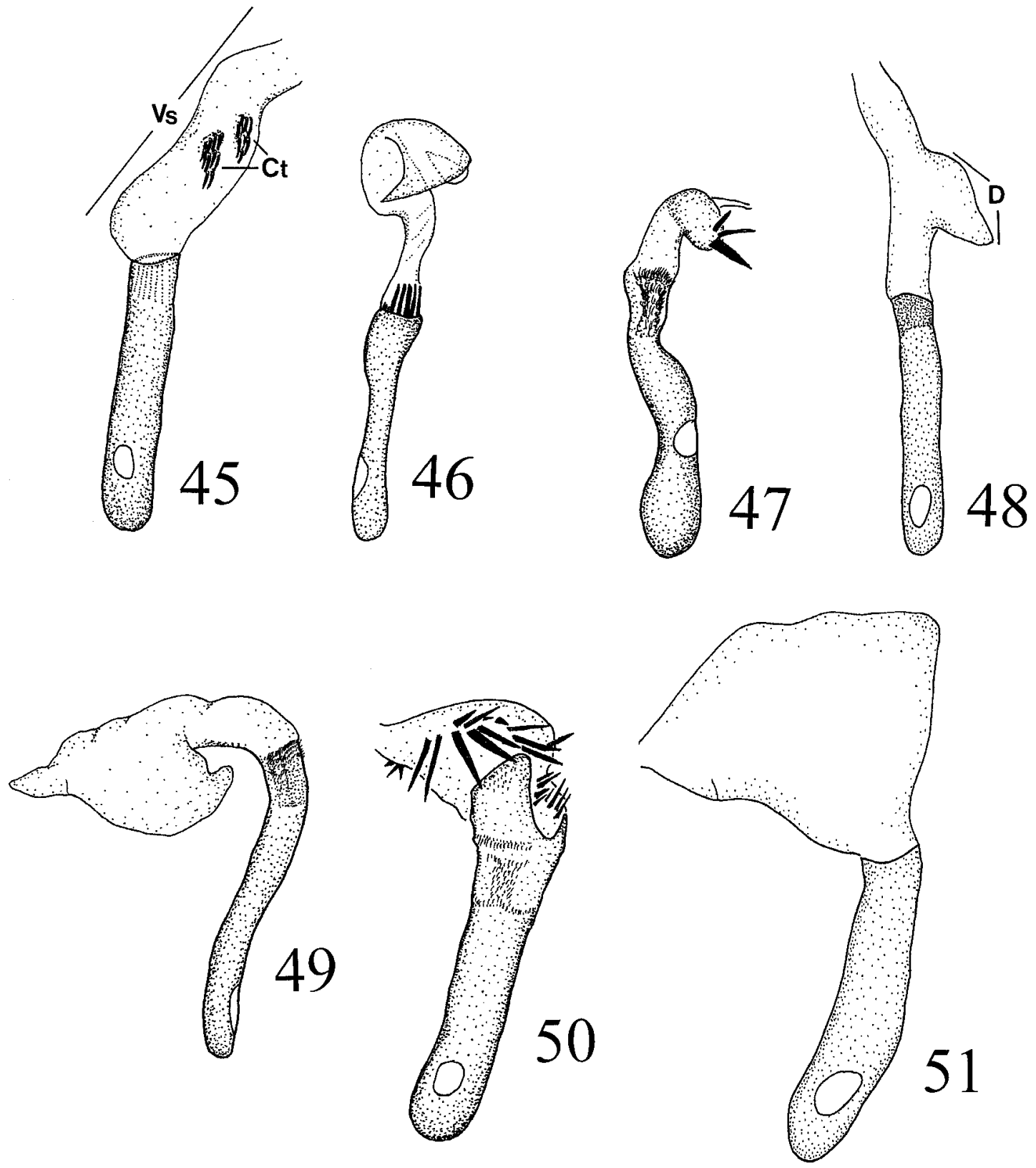

Figs. 45-51. Aedeagus with everted vesica of male genitalia. 45. Praethera praefecta, 46. Thera variata, 47. Pennithera comis, 48. Thera cyphoschema, 49. Diathera fluctuata, 50. Heterothera quadrifulta, 51. Thera exangulata. Vs vesica, Ct cornuti, D diverticulum.

ple, membraneous; (1) with wavelike striations; (2) with minute scobinations; (3) netlike and sclerotized. In Heterothera, the wall of the corpus bursae varies from simple (e.g., tephroptilus, sororcula, and quadrifulta) to having wavelike striations (e.g., $k u$ - renzovi) to minutely scobinate (e.g., incerta, yunnanensis, and eclinosis) (figs. 55, 56). In Pennithera, the wall is usually membraneous and simple (fig. 57), but in Thera, Diathera, and Praethera wavelike striations are observed (figs. 52-54). Exceptionally, 

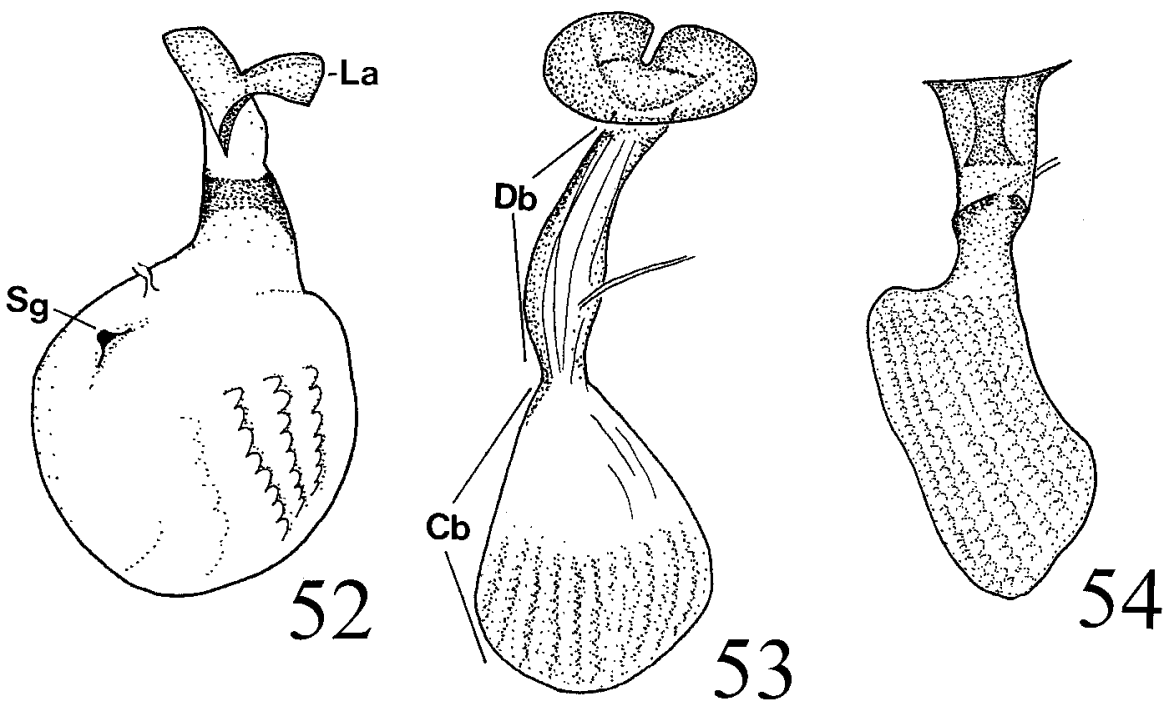

53
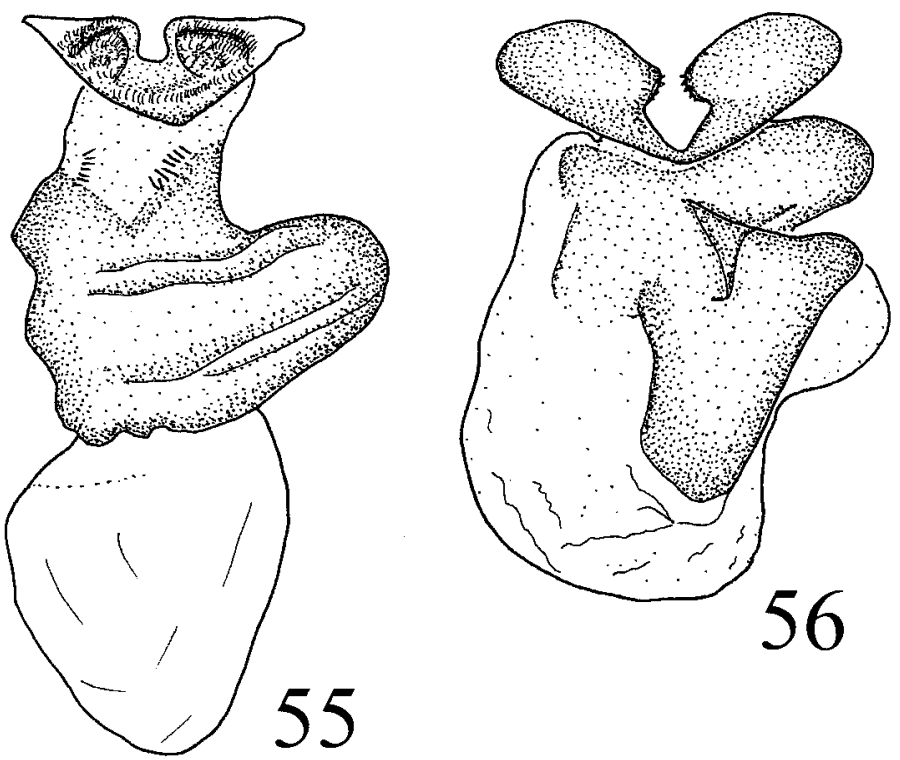

Figs. 52-56. Sterigmata, ductus, and corpus bursae of female genitalia. 52. Praethera praefecta, 53. Thera variata, 54. Diathera fluctuata, 55. Heterothera quadrifulta, 56. $H$. serraria. La lamella antevaginalis, $\mathbf{S g}$ signum, $\mathbf{D b}$ ductus bursae, $\mathbf{C b}$ corpus bursae.

Thera exangulata has a netlike, sclerotized wall (fig. 59).

\section{Cladistic Analysis}

NONA produced 45 cladograms of length 256 , consistency index $=0.30$, and retention index $=0.66$. The strict consensus clado- gram is shown in figure 60. The successive weighting approach (Farris, 1969) for these 45 cladograms was applied by NONA and after two iterations one cladogram of weighted length 7819 was stabilized (table 2, fig. $61)$. The cladogram derived from the successive weighting provides better resolved ge- 

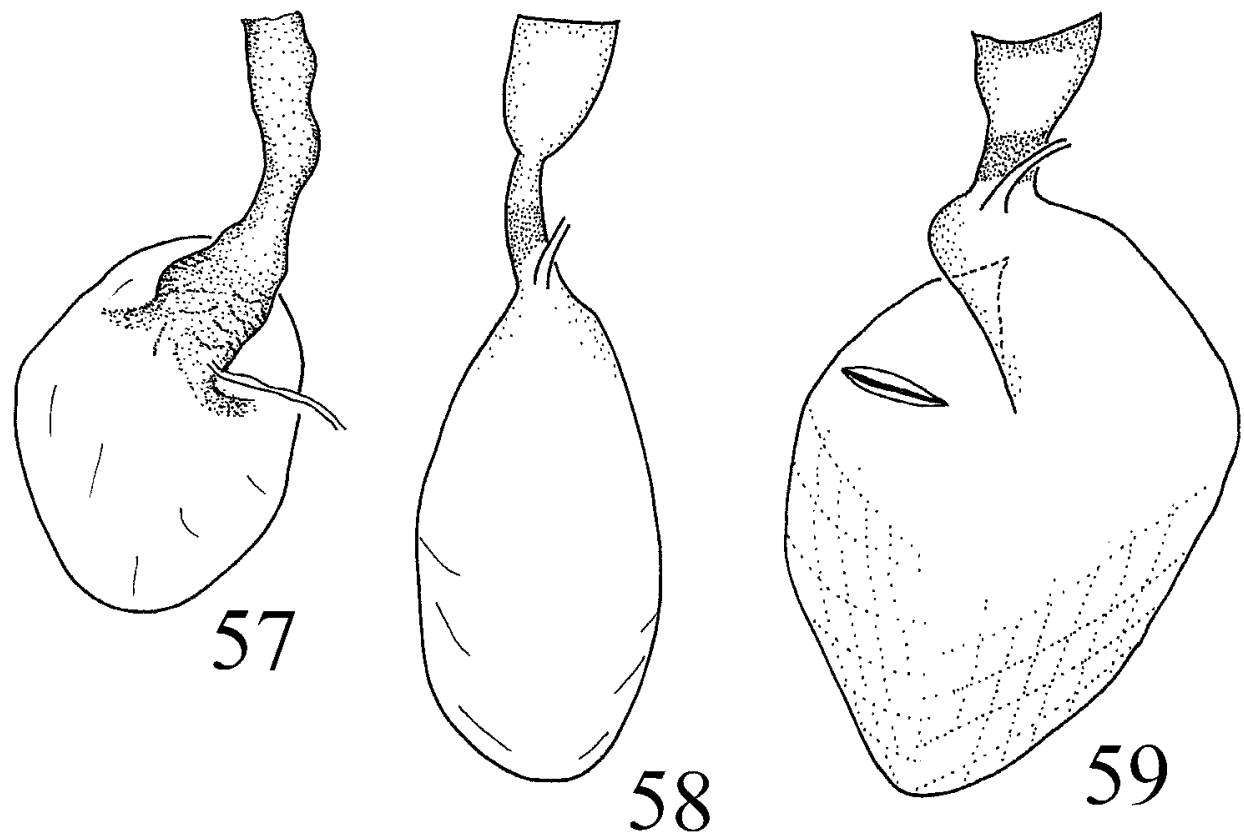

Figs. 57-59. Sterigmata, ductus, and corpus bursae of female genitalia (continued). 57. Pennithera comis, 58. Thera cyphoschema, 59. Thera exangulata.

neric interrelationships than the original cladograms: (Thera cyphoschema, (Heterothera, (Thera, (Diathera, Pennithera)))).

\section{Therini, A SyNONYM OF CidARIINI}

Both present analyses show that the tribe Therini is not monophyletic and both (figs. 60, 61) excluded Praethera from the ingroup taxa. Therefore, the results do not support the tribe Therini, and suggest that the Cidariini should be applied as the appropriate name for all ingroup taxa.

Both unweighted and successive weighting approaches support most ingroup taxa, Praethera, Thera, Pennithera, and Diathera, and the positions of two unplaced taxa, $T$. exangulata and $T$. cyphoschema, turned out to be part of a very basal member. Differences among the trees were a result of the placement of several taxa in Heterothera, Heterothera firmata, and the serraria group of Heterothera (serraria, serrataria, and kurenzovi). In the original cladograms, $H$. firmata was a basal taxon of Pennithera or formed an independent clade with the serraria group.

In his analysis for 16 species of Thera sen- su Prout, Viidalepp (1980) divided this group into three genera and four subgenera (fig. 1), suggesting that Prout's classification was unnatural. A cladistic analysis of the Cidariini resulted in some relationships different from Viidalepp's hypothesis (Choi, 1997)—specifically that Heterothera was paraphyletic. Choi also indicated that the basal node of three genera, Thera + Pennithera + Heterothera, was supported by several synapomorphies. In the present analysis my preferred cladogram (fig. 61) resolves the generic relationships without Praethera: (Fascilunaria, (Heterothera, (Thera, (Pennithera, Diathera)))), and the basal clade is supported by three synapomorphies: male antennae bipectinate (character \#0-1), antemedial line of forewing rounded or medially indented (\#61 ), and signum absent (\#47-2).

The present analysis confirms four previously known monophyletic taxa, which is partly consistent with the results of Choi (1997). However, the result indicates that Praethera is not closely related to Thera, and two new monotypic genera, Fascilunaria and Costicoma, and one combination, Thera firmata (Hübner), are suggested. Their formal classification is presented in appendix 1 . 


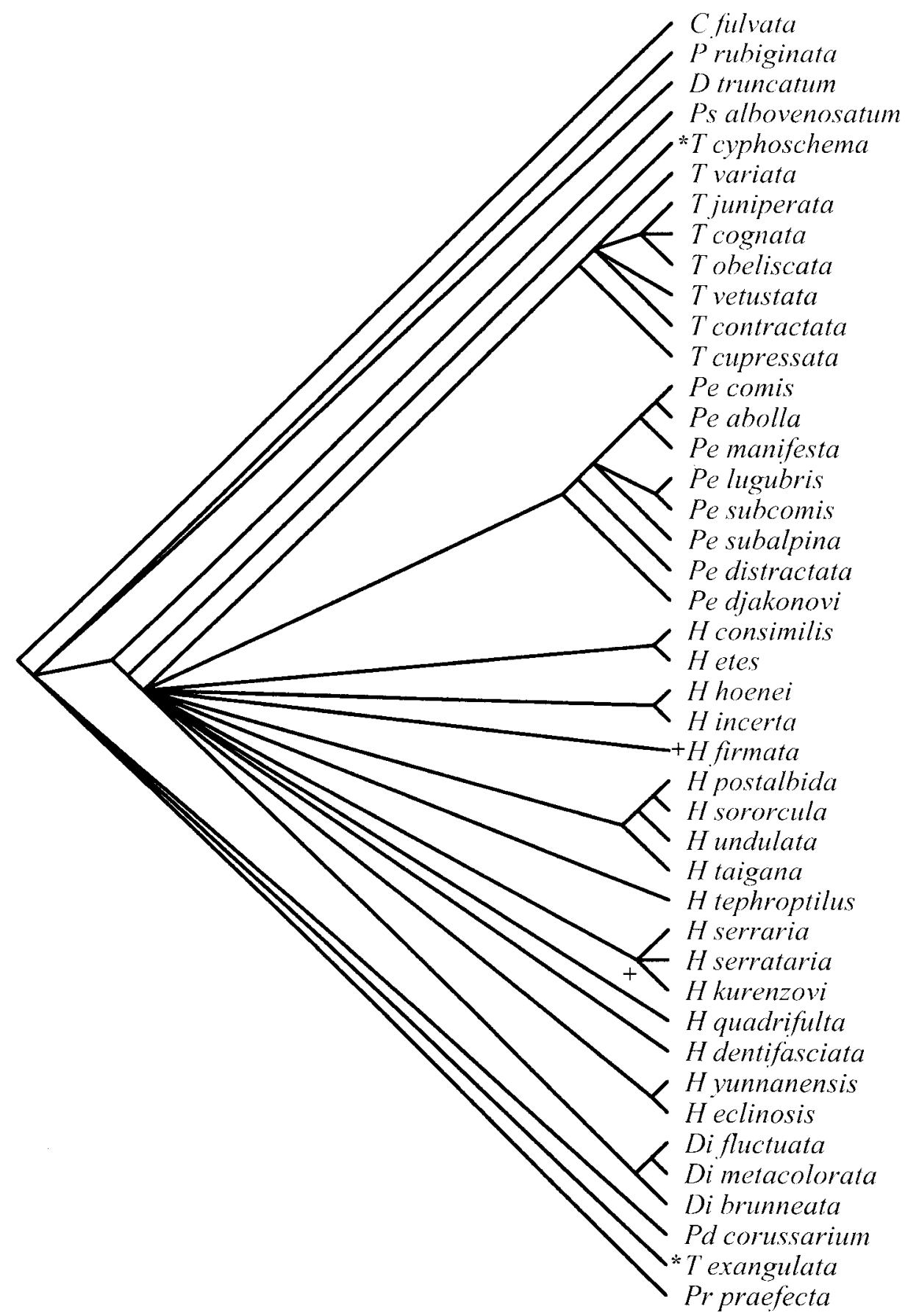

Fig. 60. Strict consensus cladogram derived from unweighted analysis using NONA. Abbreviations: C Cidaria, D Dysstroma, P Plemyria, Pe Pennithera, Pd Paradysstroma, Pr Praethera, Ps Pseudodysstroma, H Heterothera, T Thera, Di Diathera. Plus signs (+) indicate a taxon or node that produces the polytomy in the consensus cladogram; asterisks (*) indicate taxa that have ambiguous taxonomic positions. 


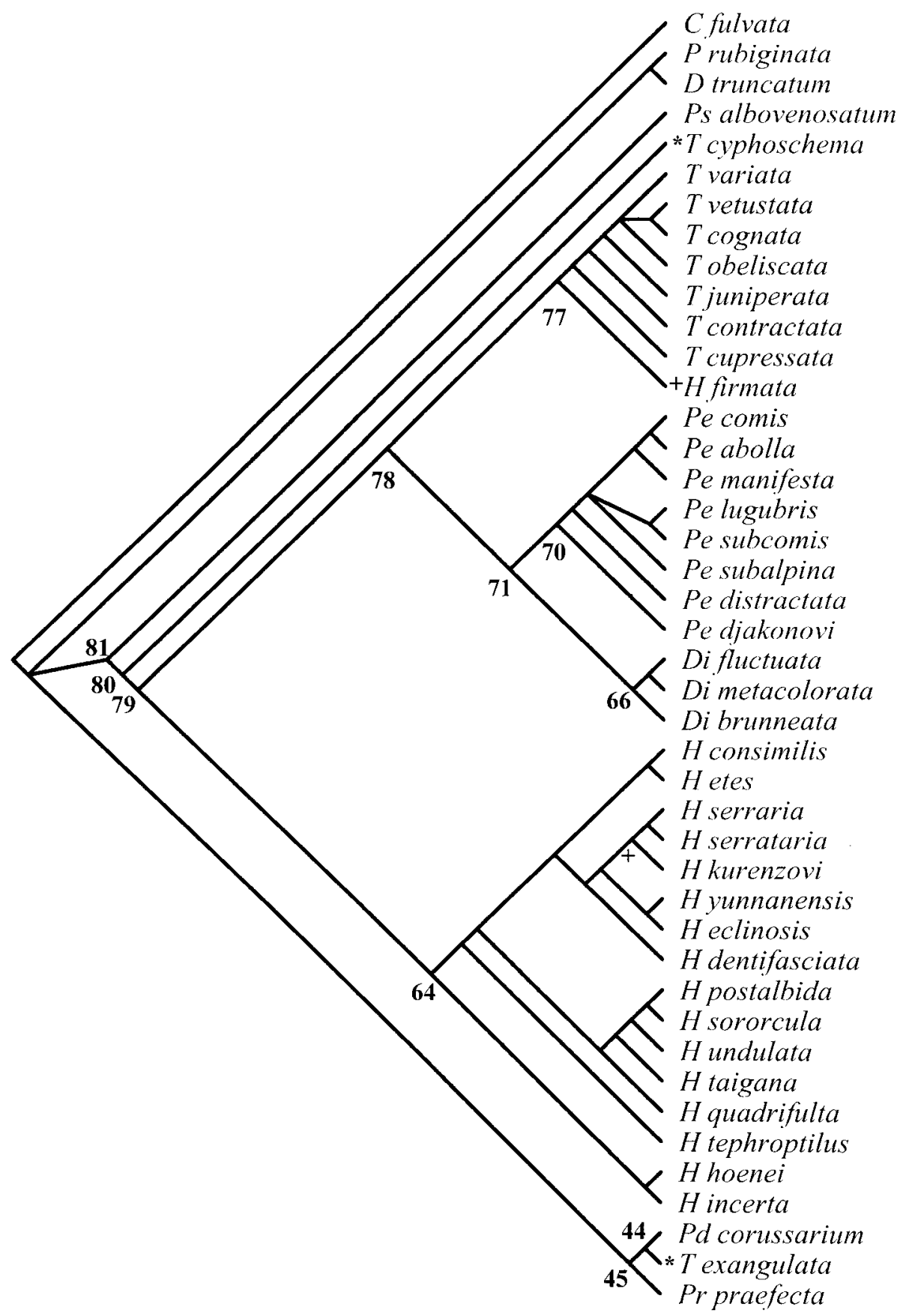

Fig. 61. One cladogram derived from successive weighting approach using NONA. See fig. 60 for generic abbreviations and symbols. Each node number is indicated. 
TABLE 2

Characters and Their Final Weights

Final weights were obtained after second iterations of the successive weighting procedure by NONA.

\begin{tabular}{lrrrrrrr}
\hline \hline Character & 0 & 1 & 2 & 3 & 4 & 5 & 6 \\
Final weight & 20 & 10 & 33 & 33 & 16 & 16 & 16 \\
Character & 7 & 8 & 9 & 10 & 11 & 12 & 13 \\
Final weight & 10 & 33 & 33 & 12 & 33 & 12 & 25 \\
Character & 14 & 15 & 16 & 17 & 18 & 19 & 20 \\
Final weight & 100 & 100 & 100 & 16 & 12 & 50 & 50 \\
Character & 21 & 22 & 23 & 24 & 25 & 26 & 27 \\
Final weight & 37 & 100 & 33 & 50 & 37 & 12 & 14 \\
Character & 28 & 29 & 30 & 31 & 32 & 33 & 34 \\
Final weight & 60 & 66 & 66 & 28 & 25 & 50 & 30 \\
Character & 35 & 36 & 37 & 38 & 39 & 40 & 41 \\
Final weight & 37 & 100 & 18 & 33 & 50 & 100 & 16 \\
Character & 42 & 43 & 44 & 45 & 46 & 47 & 48 \\
Final weight & 25 & 25 & 66 & 50 & 66 & 100 & 33 \\
\hline
\end{tabular}

\section{SYSTEMATICS}

\section{Praethera Viidalepp, 1980}

TyPE SPECIES: Cidaria praefecta Prout, 1914.

Diagnosis: Species of Praethera are characterized by the filiform male antennae, the subdorsally greatly shrunken central fascia with third cell half as wide as second, the male genitalia having a long tegumen, slender and sclerotized costa of valva upturned distally, membraneous sacculus with a medially invaginated ventral edge and two bundles of cornuti on a tubular vesica, and the female genitalia having V-shaped, sclerotized lamella postvaginalis.

DISCUSSION: In the present analysis, one species of Praethera is supported by seven autapomorphies: dorsum of the central fascia distinct with blackish scales (character \#101), anellus lobe with expanded and flattened body (\#18-1, \#21-3), valva width wider distally (\#31-0), cornuti large, spinular (\#34-1), and lamella postvaginalis with a V-shaped sclerotization (\#39-1).

Wing patterns of Praethera, especially the shape of the central fascia, place this group in Therini, but several genitalic characters differ from Thera and are closer to Dysstroma truncatum: long tegumen compared to vinculum and saccus, sacculus membra- neous, and presence of a colliculum and a signum.

Viidalepp (1980) demonstrated that Praethera is the sister group of Heterothera. He listed five apomorphic characters for Praethera: saccus massive and round; sacculus membraneous; last tergite of female abdomen quadrilateral; ductus bursae modified; and both the collar of the bursa copulatrix and sterigma well-developed and strongly sclerotized. However, the present analysis shows that Praethera is placed as the sister taxon of (Paradysstroma corussarium + Costicoma exangulata), not Heterothera. Two species of Praethera are known, $P$. praefecta (Prout, 1914) and P. anomala (Inoue, 1954), but the validity of the latter species is uncertain (Viidalepp, 1996). Both species occur in east Asia.

\section{Costicoma, new genus}

TyPE SPECIES: Perizoma exangulata Warren, 1909.

Diagnosis: Species of Costicoma can be characterized by the forewing with blackish central fascia medially and dorsally greatly tapered, the valva with sclerotized costa and long hairs on the middle of costa, cornuti absent from vesica, and the female genitalia having the corpus bursae with a large, threadlike signum.

DESCRIPTION: Antenna filiform in both sexes. Frons mixed with ochreous and brownish scales. Labial palp short. Legs dark brownish, foreleg tarsal joints distinct with ochreous scales. Metathorax dorsum with blackish tufts. Forewing basally dark brown; basal line dentate, slanted; central fascia blackish, costally bulged; subterminal line whitish, scalloped; apical streak blackish. Hindwing whitish, basally tinged with blackish scales; postmedial line blackish. Male genitalia. Uncus long, basally tapering. Tegumen dome-shaped. Saccus rounded, medially expanded. Anellus lobe long, rod shaped, apically with long hairs. Transtilla thin, rounded, sclerotized. Valva slender; costa slender, distally with long hairs; sacculus membraneous. Aedeagus cylindrical with large, saclike vesica; cornutus absent. Female genitalia. Papillae anales simple. Anterior apophyses about $3 / 5$ length of posterior apophy- 
TABLE 3

Apomorphies in Cladogram Derived from Successive Weighting Approach Shown in Figure 61

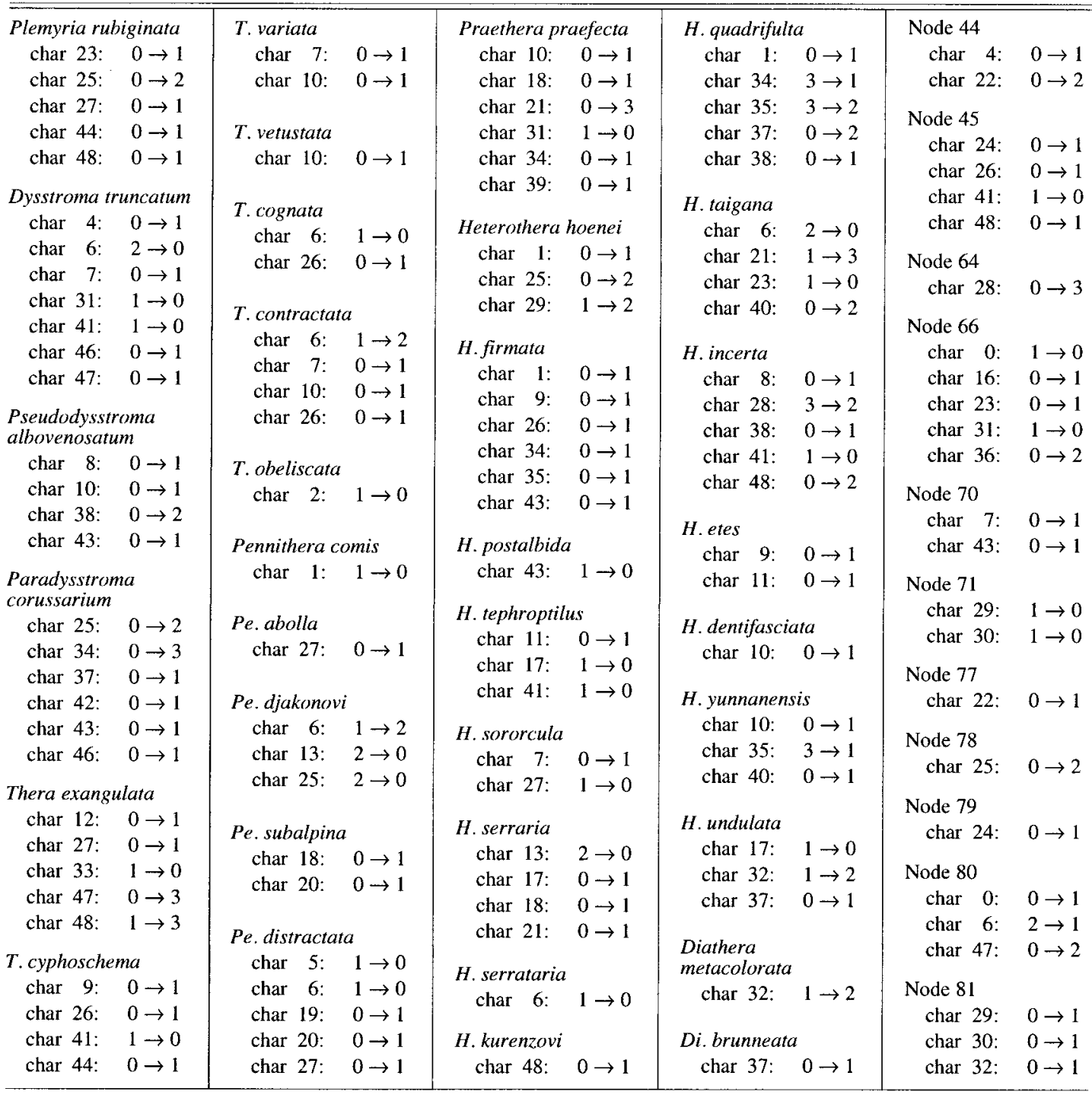

ses. Sterigma membraneous, antrum broad, funnel-shaped. Ductus bursae short with a colliculum. Corpus bursae large, subovate, with a long, threadlike signum.

DisCUSSION: There are four autapomorphies: uncus long (character \#12-1); ventral edge of sacculus flat (\#27-1); vesica large, saclike (\#33-0), signum large, threadlike (\#47-3), and wall of corpus bursae with netlike sclerotizations (\#48-3).

Costicoma exangulata is similar to Cidaria deletaria Hampson in the male genitalia having long hairs on the costa, but differs in the wing pattern and female genitalia (Choi, 1998a). Results here place $C$. exangulata as the sister taxon to $P$. corussarium, and the basal clade is supported by two apomorphic characters: blackish metathorax and thin, round transtilla. This taxon was included in the Therini (Prout, 1938), but is distinct from other species of Therini based on several apomorphic characters (Choi, 1998a): costa of valva strongly sclerotized with long hairs; large saclike vesica without a cornutus; os- 
tium bursae broad; colliculum present; signum large, threadlike, and wall of corpus bursae with netlike sclerotization. Differences in wing pattern and genitalia separate $e x$ angulata from its sister genus Paradysstro$m a$, suggesting a new genus, Costicoma. It is only known from northern India.

ETYMOLOGY: The name refers to long hairs on the costa in the male genitalia, Costa $($ Costa $)+$ Hairs (Coma).

\section{Fascilunaria, new genus}

Type Species: Cidaria cyphoschema Prout, 1926.

Diagnosis: Synapomorphies for Fascilunaria include bipectinate male antennae, the thin and crescent central fascia of the forewing with a discal dot united with costal part of the antemedial line, the male genitalia with a thick and short uncus, a saccular process, cornuti absent from vesica and the female genitalia with a simple sterigma, anterior to the antrum funnel shaped, a colliculum, and the large corpus bursae without a signum.

Description: Antenna. Male bipectinate with short pectination; female filiform. Frons white and ochreous scales. Labial palp long, about twice the eye diameter. Legs brownish, foreleg tarsal joints distinct with white scales. Metathorax dorsum with blackish tufts. Forewing grayish; basal line blackish, slanted; antemedial line blackish, medially strongly indented; postmedial line medially projected; central fascia thin. Hindwing whitish, with a black discal dot; postmedial line very weak. Male genitalia. Uncus short, thick. Tegumen dome shaped. Anellus lobe digitiform, medially and apically with hairs. Saccus rounded, medially projected. Valva weakly sclerotized; costa distally projected; sacculus with a process. Aedeagus slender, rod shaped, with a tubular vesica; cornutus absent. Female genitalia. Papillae anales simple. Anterior apophyses half of posterior apophyses in length. Sterigma simple, dorsally with thin, sclerotized stripes; antrum large, funnel shaped. Ductus bursae short, membraneous, with a colliculum. Corpus bursae large, subspherical; signum absent.

Discussion: Fascilunaria cyphoschema has four apomorphies: discal dot united with the costal part of antemedial line (character \#9-1), costa of the male valva with a distal expansion (\#26-1), ductus bursae short (\#410 ), and ductus bursae anterior to antrum funnel shaped (\#44-1).

$F$. cyphoschema is similar to several members of Heterothera in the shape of the central fascia of the forewing as well as the anellus lobe and saccular process of the male genitalia. However, other aspects of the male and female genitalia of $F$. cyphoschema are different from those of Heterothera: uncus thick, short, and less sclerotized; cornutus absent; sterigma simple; anterior to antrum funnel shaped; membraneous dustus bursae with a colliculum, and corpus bursae large. In the present analysis, the results demonstrate that $F$. cyphoschema forms a basal lineage of the clade comprising Heterothera + Thera + Pennithera + Diathera (fig. 61). This species is known from southwestern China, northern Vietnam and Burma (Choi, 1998a).

ETYMOLOGY: The name refers to the shape of the central fascia of forewing, central fascia (Fascia) + crescent (lunaria).

Thera Stephens, 1831

TyPE SPECIES: Geometra variata [Denis and Schiffermüller, 1775].

DiAGNOSIS: Members of Thera have filiform male antennae; central fascia of the forewing thin and medially and dorsally narrowed; male genitalia with hook-shaped uncus, transtilla thin, platelike, saccus medially projected, costa of valva strongly sclerotized with medial and distal projections, sacculus large, rounded, aedeagus slender with spinular processes distally; and female genitalia having lamella antevaginalis sclerotized, rounded; ductus bursae thin, long without a colliculum and the corpus bursae ovate without a signum.

DiscUSSION: All species of Thera (except firmata) are united by four synapomorphies: male antenna filiform (character \#0-0), saccus medially projected (\#23-2), dorsal edge of sacculus vertically sclerotized (\#28-1), and lamella antevaginalis two doughnutlike structures without a seta (\#37-2). The basal clade comprising Thera and T. firmata is 
supported by one synapomorphy: transtilla large, platelike (\#22-1).

Stephens (1831) proposed the genus Thera by separating it from Chesias Treitschke based on differences of the palpi, wing pattern and host plant (fir or juniper). Viidalepp (1980) defined the monophyly of Thera: saccus tender and round; costa and sacculus of valva distinct; ductus bursae membraneous; and sterigma sclerotized. Choi (1997) redefined the monophyly of the genus using 11 synapomorphies and listed four uniquely derived characters: costa of valva with a medial projection; cucullus large; and cornuti on vesica fewer and arranged in a crown shape. About 12 species of Thera are known and they occur widely throughout the Holarctic region.

T. firmata has seven autapomorphies: vertex distinct with whitish scales (character \#11), discal dot of forewing united to the costal part of antemedial line (\#9-1), costa of valva with a distal expansion (\#26-1), cornuti on vesica large and spinular and grouped into one-patch (\#34-1, \#35-1), and ductus bursae sclerotized (\#48-1). The species T. firmata is placed at the basal node of Thera in the successive weighting approach (fig. 61), but as a member of Heterothera (fig. 60). The status of this species was first discussed by Pierce (1914). He distinguished it from Thera based on structures of the genitalia. Later, Viidalepp (1980) moved it to Pennithera, on the basis of two apomorphies: indistinct sacculus and shortly bipectinate male antenna. However, Choi (1997) subsequently combined it with Heterothera, using three synapomorphies: apical streak of forewing absent, anellus lobe expanded, and saccus flat and broad. In the present analysis, firmata is again associated with Thera.

\section{Pennithera Viidalepp, 1980}

TyPe SPECIES: Larentia comis Butler, 1879.

Diagnosis: Members of Pennithera have male antennae bipectinate; forewing with a black dot at dorsum between basal and antemedial line, ante and postmedial lines strongly scalloped; tegumen short with narrow anterior end; costa of valva sclerotized with large basal and distal projections; aedeagus bent; vesica with several spinular cor- nuti; female seventh sternite sclerotized; sterigma simple; ductus bursae long, sclerotized without a colliculum; and corpus bursae small and ovate without a signum.

Discussion: Eight species of Pennithera are united by two synapomorphies: forewing between basal and antemedial lines tinged with black scales (\#7-1) and ductus bursae sclerotized (\#43-1). Viidalepp (1980) proposed the genus Pennithera and included three species, $P$. comis (Butler), $P$. djakonovi (Kurentzov) and P. firmata (Hübner), based on two apomorphies: saccus massive and round, and last tergite of the female abdomen telescopic. Inoue (1982, 1986a) added five species, mainly from Taiwan: $P$. abolla (Inoue), $P$. subcomis (Inoue), P. lugubris Inoue, $P$. manifesta Inoue, and $P$. subalpina Inoue. Choi (1998a) combined one additional species Thera distractata Sterneck (1928).

Inoue (1986a, 1986b) noted that Pennithera is distinguished from Viidaleppia, a junior synonym of Heterothera, by quadripectinate male antennae with slender branches, costa of valva half-expanded basally, greatly invaginated medially and rounded distally; sacculus unsclerotized, cornuti few and thornlike; simple and unsclerotized lamellae ante- and postvaginalis, and slender ductus bursae. Choi (1997) listed six synapomorphies of Pennithera: male antenna with long pectinations; slender sacculus; female ninth abdominal segment long, nearly the same length as eighth tergite; long and sclerotized antrum; and twisted ductus bursae.

Diathera Choi, 1999

\section{Type Species: Diathera fluctuata Choi, 1999.}

Diagnosis: Members of Diathera have male antennae filiform; long uncus; juxta with short, strongly sclerotized hairs; costa of valva with minute dentate processes basally, greatly expanded medially; vesica without a cornutus; female eighth sternite scobinate; ductus bursae short, sclerotized, and the corpus bursae slender with scalloped processes on the wall.

Discussion: The three species of Diathera, all from southwestern China, are united by five synapomorphies: male antenna filiform (character \#0-0), juxta with strongly sclero- 
tized hairs (\#16-1), medially invaginated saccus (\#23-1), valva wider distally (\#31-0), and female seventh sternite scobinate (\#36-2).

The species of this genus are similar to Pennithera externally, especially in the strongly scalloped ante and postmedial lines of the forewing. However, the structure of the male antennae and the male and female genitalia separate Diathera from Pennithera.

\section{Heterothera Inoue, 1943}

TyPE SPeCIES: Cidaria postalbida Wileman, 1911. = Viidaleppia Inoue, 1982 [synonymized by Choi, 1997: 311]. Type species: Cidaria quadrifulta Prout, 1938.

DiAGNOSIS: Members of Heterothera are variable in the male antennae, the shape of central fascia of the forewing, and the genitalia. However, they generally show the following features: central fascia of the forewing rather thick, outwardly oblique; tegumen same length as vinculum and saccus; saccus medially invaginated; costa of valva sclerotized with medial or distal expansion; sacculus sclerotized with spinular process; cucullus with long, dense hairs; aedeagus long, cylindrical; vesica with several scattered, spinular cornuti; lamella ante- and postvaginalis complicated with spinular or patchlike structures; ductus bursae thick with sclerites on the wall; and corpus bursae without a signum.

DisCUSSION: In the present analysis, one synapomorphy, dorsal edge of sacculus scalloped (character \#28-3), supports the grouping of 16 species of Heterothera. Inoue (1943) proposed the genus Heterothera based mainly on male genital characters: absence of uncus (this character was found to be incorrect; see Choi, 1997); long anal tube; saccus basally flat and broad; costa weakly sclerotized, and sacculus well-developed. Viidalepp (1980) noted that the broad, angulated saccus is the main derived character for the genus. As noted above, Inoue (1982) erected another genus, Viidaleppia. However, Choi (1997) synonymized Viidaleppia under Heterothera and listed seven synapomorphies: sacculus process (or harpe) small; cucullus with hairs; saccus medially invaginated; cornuti scattered on vesica; lamella antevaginalis with semicircular process; ductus bursae relatively thick, and wall of ductus bursae with sclerotized processes.

\section{Key to Genera Examined Based on Genitalia}

1. Tegumen longer than total length of vinculum and saccus; corpus bursae with a signum Praethera (figs. 2, 21, 24, 29, 37, 45, 52)

- Tegumen shorter than total length of vinculum and saccus; corpus bursae without a signum $\ldots \ldots \ldots \ldots \ldots \ldots \ldots$

2. Sacculus sclerotized with a process; sterigma of female genitalia developed with sclerites $\ldots \ldots \ldots \ldots \ldots \ldots$

- Sacculus without a process; sterigma simple, without modification ............5

3. Vesica without a cornutus; ductus bursae membraneous ..............4

- Vesica with cornuti; ductus bursae sclerotized ... Heterothera (figs. 3-7, 22, 23, 28, 35, $36,41,42,50,55,56)$

4. Uncus hooked; saccus strongly projected; aedeagus with distal spinular processes; sterigma with sclerotized processes ..... ... Thera (figs. 8, 18, 25, 30, 38, 46, 53)

- Uncus short and thick; saccus rounded; aedeagus distal part without spinular process; sterigma simple, membraneous ......... ...... Fascilunaria (figs. 17, 44, 48, 58)

5. Costa of male valva with long hairs; corpus bursae with a long signum ......... ....... Costicoma (figs. 16, 43, 51, 59)

- Costa without long hairs; corpus bursae without a signum .............6

6. Costa of male valva with a large basal expansion; vesica with cornuti; ductus bursae sclerotized .. Pennithera (figs. 11-14, 20, $27,32,33,40,47,57)$

- Costa with a large distal expansion; vesica without cornuti; ductus bursae membraneous ... Diathera (figs. 11, 26, 31, 39, 49, 54)

\section{REFERENCES}

Choi, S.-W.

1997. A phylogenetic study on genera of Cidariini from the Holarctic and the IndoAustralian areas (Lepidoptera: Geometridae, Larentiinae). Syst. Entomol. 22: 287-312.

1998a. Systematics of the genus Heterothera Inoue (Lepidoptera, Geometridae: Larentiinae). Tijdschr. Entomol. 141: 1947.

1998b. Taxonomic review of two genera Pseudodysstroma Heydemann and Paradysstroma gen. n. (Lepidoptera: Geo- 
metridae, Larentiinae). Tinea 15: 228239.

1999. Taxonomic review of a new genus Diathera gen. n. from Southeast Asia (Lepidoptera, Geometridae: Larentiinae). J. Nat. Hist. 33: 1039-1048.

Dugdale, J. S.

1988. Lepidoptera-Annotated catalogue, and keys to family-group taxa. Fauna N. Z. 14: 171-191.

Farris, J. S.

1969. A successive approximations approach to character weighting. Syst. Zool. 18: 374-385.

Forbes, W.T.M.

1948. Lepidoptera of New York and neighboring states. Part II. Cornell Univ. Agric. Exp. Stn. Mem. 274: 10-175.

Goloboff, P. A.

1993. NONA, Ver. 1.5. San Miguel de Tucuman.

Holloway, J. D.

1997. The moths of Borneo: family Geometridae, subfamilies Sterrhinae and Lar-

Inoue, $\mathrm{H}$. entiinae. Malay. Nat. J. 51: 1-242.

1943. New and little known Geometridae from Japan. Trans. Kansai Entomol. Soc. 12: 1-25.

1982. Geometridae 1: 425-572. In H. Inoue et al., Moths of Japan. Tokyo: Kodansha.

1986a. Further new and unrecorded species of the Geometridae from Taiwan with some synonymic notes (Lepidoptera). Bull. Fac. Domest. Sci., Otsuma Woman's Univ. 22: 211-267.

1986b. Descriptions and records of some Japanese Geometridae (VI). Tinea 12: 4571.

Miller, J. S.

1991. Cladistics and classification of the Notodontidae (Lepidoptera: Noctuoidea) based on larval and adult morphology. Bull. Am. Mus. Nat. Hist. 204: 1-230.

Pierce, F. N.

1914. The genitalia of the group Geometridae of the Lepidoptera of the British Is-

Prout, L. B. lands. Liverpool. 88 pp. +48 pls.

1914. Geometridae. In A. Seitz (ed.), Die Grossschmetterlinge der Erde-Die Palaearktischen Spanner. 1(IV): 216-219. Stuttgart: Verlag A. Kernen.

1938. Geometridae. Ibid. (Suppl.): 110-170. Stuttgart: Verlag A. Kernen.

1941. Geometridae. In A. Seitz (ed.), Die Gross Schmetterlinge des Indoaustral- ischen Faunengebietes. 12: 323-324. Stuttgart: Verlag A. Kernen.

Scoble, M. J.

1992. The Lepidoptera: form, function, and diversity. New York: Oxford Univ. Press.

Stephens, J. F.

1829-1831. Illustrations of British Entomology. Haustellata 3. London: Baldwin and Cradock.

Viidalepp, J.

1980. Geometrid moths of the genus Thera Steph. in the fauna of the USSR (Lepidoptera). Tartu Riikliku ûlikooli Toimetised 13(516): 54-84. [in Russian with English summary]

1996. Checklist of the Geometridae (Lepidoptera) of the former U.S.S.R. Stenstrup: Apollo Books. 111 pp.

\section{APPENDIX 1}

Formal Classification of Ingroup Taxa

Asterisks (*) indicate unexamined taxa.

Costicoma n. gen. exangulata (Warren, 1909) n. comb.

Praethera Viidalepp, 1980

*anomala (Inoue, 1954)

praefecta (Prout, 1914)

Diathera Choi, 1999 brunneata Choi, 1999

fluctuata Choi, 1999

metacolorata Choi, 1999

Pennithera Viidalepp, 1980 abolla (Inoue, 1943)

comis (Butler, 1879)

distractata (Sterneck, 1928)

djakonovi (Kurentzov, 1950)

lugubris Inoue, 1986

manifesta Inoue, 1986

subalpina Inoue, 1986

subcomis Inoue, 1978

Fascilunaria n. gen.

cyphoschema (Prout, 1926) n. comb.

Thera Stephens, 1829

* britannica Turner, 1925

cognata (Thunberg, 1792)

contractata (Packard, 1873)

cupressata (Geyer, 1831)

firmata (Hübner, 1822) rev. comb.

juniperata (Linnaeus, 1758)

*latens Barnes \& McDunnough, 1917

obeliscata (Hübner, 1787)

*otsi (Dyar, 1904)

variata (Denis \& Schiffermüller, 1775)

*variolata (Staudinger, 1899) 
vetustata (Denis \& Schiffermüller, 1775)

Heterothera Inoue, 1943

consimilis (Warren, 1888)

* comitabilis (Prout, 1923)

dentifasciata (Hampson, 1895)

* distinctata Choi, 1998

eclinosis Choi, 1998

etes (Prout, 1926)

hoenei Choi, 1998

incerta Inoue, 1986

kurenzovi Choi, Viidalepp \& Vasjurin, 1998

*mussooriensis Choi, 1998

*obscurata Choi, 1998

postalbida (Wileman, 1911)

quadrifulta (Prout, 1938)

serraria (Lienig, 1846)

serrataria (Prout, 1914)

sororcula (Bastelberger, 1909)

* stamineata Choi, 1998

taigana (Djakonov, 1926)

tephroptilus (Heydemann, 1961)

*triangulata Choi, 1998

undulata (Warren, 1888)

yunnanensis Choi 1998

\section{APPENDIX 2 \\ Reanalysis of Viidalepp's Data Set}

Here I present a reanalysis of the data presented by Viidalepp (1980). Fifteen characters appeared in the original diagram and most of them were binary, except for four characters (characters 4, 6, $7,14)$ that he stated plesiomorphic, intermediate and apomorphic. I rescored these characters as multistate and treated them as additive in the analysis, because Viidalepp considered that the intermediate state was between the plesio- and apomorphy. Character number 15 was treated as inapplicable in the species of Thera and Heterothera because the male antennae of those species are filiform. The recoded data matrix was analyzed by Hennig86 using the implicit enumeration (ie*) using an all zero outgroup. This analysis resulted in 55 equally parsimonious trees with 33 steps, 57 consistency index, and 82 retention index. The strict consensus is shown in figure $1 \mathrm{~B}$.

\begin{tabular}{|c|c|}
\hline & $\begin{array}{r}111111 \\
123456789012345 \\
\end{array}$ \\
\hline A. quadrifulta & 000010000101000 \\
\hline A. serrataria & 000010010101000 \\
\hline A. serraria & 000010010101000 \\
\hline A. taigana & 000011011101101 \\
\hline A. djakonovi & 000101101000000 \\
\hline A. comis & 000101101001100 \\
\hline A. firmata & 000102201101000 \\
\hline T. praefecta & $10011110100102-$ \\
\hline T. anomala & $10011110100102-$ \\
\hline$T$. juniperata & $10020220110102-$ \\
\hline T. cognata & $10020220111002-$ \\
\hline T. obeliscata & $10020220111011-$ \\
\hline T. albonigrata & $10020220111011-$ \\
\hline T. bellisi & $10020220111011-$ \\
\hline T. variata & $10020220111012-$ \\
\hline H. postalbida & $11100220010102-$ \\
\hline
\end{tabular}

\section{Characters and Character States}

1. Antenna of male pectinate (0), filiform (1).

2. Sacculus processes simply pointed $(0)$, bifid (1).

3. Uncus present (0), absent (1).

4. Saccus heavily sclerotized and broad, angulated platelike (0), massive and rounded (1), medially projected (2).

5. The last tergite of female abdomen with long apophyses and telescopic (0), with short apophyses and strongly sclerotized to limit the mobility of ovipositor (1).

6 . The ductus and the collar of corpus bursae strongly sclerotized (0), intermediate (1), membraneous (2).

7. Sterigma well developed and sclerotized (0), intermediate (1), simple and slightly sclerotized (2).

8. Eighth sternite of female abdomen simple (0), fused to sterigma (1).

9. Costa indistinct and fused to other part of valva (0), distinct (1).

10. Sacculus indistinct and fused to other part of valva (0), distinct (1).

11. Cornuti present in vesica (0), present in the dorsal part of aedeagus, corona-shaped (1).

12. Cornutus absent (0), present (1).

13. Uncus short (0), long (1).

14. Antenna of male pectinate (0), filiform with constricted or rounded ventral surfaces (1), filiform with cylindrical antennomeres (2).

15. Antennal pectination short (1), long (0). 
Recent issues of the Novitates may be purchased from the Museum. Lists of back issues of the Novitates and Bulletin published during the last five years are available at World Wide Web site http://nimidi.amnh.org. Or address mail orders to: American Museum of Natural History Library, Central Park West at 79th St., New York, NY 10024. TEL: (212) 769-5545. FAX: (212) 7695009. E-MAIL: scipubs@amnh.org

(0) This paper meets the requirements of ANSI/ NISO Z39.48-1992 (Permanence of Paper). 